Cochrane Database of Systematic Reviews

\title{
Gabapentin add-on treatment for drug-resistant focal epilepsy
} (Review)

Panebianco M, Al-Bachari S, Weston J, Hutton JL, Marson AG

Panebianco M, Al-Bachari S, Weston J, Hutton JL, Marson AG.

Gabapentin add-on treatment for drug-resistant focal epilepsy.

Cochrane Database of Systematic Reviews 2018, Issue 10. Art. No.: CD001415.

DOI: 10.1002/14651858.CD001415.pub3.

www.cochranelibrary.com 
TABLE OF CONTENTS

HEADER 1

ABSTRACT

PLAIN LANGUAGE SUMMARY

SUMMARY OF FINDINGS

BACKGROUND

OBJECTIVES

METHODS

RESULTS

Figure 1.

Figure 2.

Figure 3.

Figure 4.

DISCUSSION

AUTHORS' CONCLUSIONS

ACKNOWLEDGEMENTS

REFERENCES

CHARACTERISTICS OF STUDIES

DATA AND ANALYSES

Analysis 1.1. Comparison 1 Gabapentin versus placebo, Outcome 1 Reduction in seizure frequency $\geq 50 \%$.

Analysis 1.2. Comparison 1 Gabapentin versus placebo, Outcome 2 Treatment withdrawal.

Analysis 1.3. Comparison 1 Gabapentin versus placebo, Outcome 3 Adverse effects.

ADDITIONAL TABLES

APPENDICES

WHAT'S NEW

HISTORY

CONTRIBUTIONS OF AUTHORS

DECLARATIONS OF INTEREST

SOURCES OF SUPPORT

DIFFERENCES BETWEEN PROTOCOL AND REVIEW

INDEX TERMS 
[Intervention Review]

\section{Gabapentin add-on treatment for drug-resistant focal epilepsy}

Mariangela Panebianco ${ }^{1}$, Sarah Al-Bachari², Jennifer Weston ${ }^{1}$, Jane L Hutton ${ }^{3}$, Anthony G Marson ${ }^{1}$

1Department of Molecular and Clinical Pharmacology, Institute of Translational Medicine, University of Liverpool, Liverpool, UK.

2Department of Neurology, Royal Preston Hospital, Preston, UK. ${ }^{3}$ Department of Statistics, University of Warwick, Coventry, UK

Contact address: Mariangela Panebianco, Department of Molecular and Clinical Pharmacology, Institute of Translational Medicine, University of Liverpool, Clinical Sciences Centre for Research and Education, Lower Lane, Liverpool, L9 7LJ, UK. m.panebianco@liverpool.ac.uk, dott_mariangela@hotmail.com.

Editorial group: Cochrane Epilepsy Group

Publication status and date: New search for studies and content updated (no change to conclusions), published in Issue 10, 2018.

Citation: Panebianco M, Al-Bachari S, Weston J, Hutton JL, Marson AG. Gabapentin add-on treatment for drug-resistant focal epilepsy. Cochrane Database of Systematic Reviews 2018, Issue 10. Art. No.: CD001415. DOI: 10.1002/14651858.CD001415.pub3.

Copyright @ 2018 The Cochrane Collaboration. Published by John Wiley \& Sons, Ltd.

\section{A B S T R A C T}

\section{Background}

This is an updated version of the Cochrane Review previously published in 2013.

Most people with epilepsy have a good prognosis and their seizures are well controlled by a single antiepileptic drug, but up to $30 \%$ develop drug-resistant epilepsy, especially those with focal seizures. In this review, we summarised the evidence from randomised controlled trials (RCTs) of gabapentin, when used as an add-on treatment for drug-resistant focal epilepsy.

\section{Objectives}

To evaluate the efficacy and tolerability of gabapentin when used as an add-on treatment for people with drug-resistant focal epilepsy.

\section{Search methods}

For the latest update, we searched the Cochrane Register of Studies (CRS Web, 20 March 2018), which includes the Cochrane Epilepsy Group's Specialized Register and the Cochrane Central Register of Controlled Trials (CENTRAL), MEDLINE (Ovid, 1946 to 20 March 2018 ), ClinicalTrials.gov (20 March 2018) and the World Health Organization International Clinical Trials Registry Platform (ICTRP, 20 March 2018). We imposed no language restrictions.

\section{Selection criteria}

Randomised, placebo-controlled, double-blind, add-on trials of gabapentin in people with drug-resistant focal epilepsy. We also included trials using an active drug control group or comparing different doses of gabapentin.

\section{Data collection and analysis}

For this update, two review authors independently selected trials for inclusion and extracted the relevant data. We assessed the following outcomes: seizure frequency, seizure freedom, treatment withdrawal (any reason) and adverse effects. Primary analyses were intentionto-treat. We also undertook sensitivity best-case and worst-case analyses. We estimated summary risk ratios (RR) for each outcome and evaluated dose-response in regression models.

\section{Main results}

We included 12 trials representing 2607 randomised participants. We combined data from six trials in meta-analyses of 1206 randomised participants. The overall RR for reduction in seizure frequency of $50 \%$ or more compared to placebo was 1.89 (95\% confidence interval (CI) 1.40 to 2.55; 6 trials, 1206 participants; moderate-quality evidence). Dose regression analysis (for trials in adults) showed increasing efficacy with increasing dose, with $25.3 \%$ (19.3 to 32.3) of people responding to gabapentin $1800 \mathrm{mg}$ compared to $9.7 \%$ on placebo, a $15.5 \%$ 
increase in response rate ( 8.5 to 22.5$)$. The RR for treatment withdrawal compared to placebo was 1.05 ( $95 \% \mathrm{Cl} 0.74$ to $1.49 ; 6$ trials, 1206 participants; moderate-quality evidence). Adverse effects were significantly associated with gabapentin compared to placebo. RRs were as follows: ataxia 2.01 (99\% Cl 0.98 to $4.11 ; 3$ studies, 787 participants; low-quality evidence), dizziness 2.43 ( $99 \% \mathrm{Cl} 1.44$ to $4.12 ; 6$ studies, 1206 participants; moderate-quality evidence), fatigue 1.95 (99\% Cl 0.99 to 3.82; 5 studies, 1161 participants; low-quality evidence) and somnolence 1.93 (99\% Cl 1.22 to 3.06; 6 studies, 1206 participants; moderate-quality evidence). There were no significant differences for the adverse effects of headache (RR $0.79,99 \% \mathrm{Cl} 0.46$ to $1.35 ; 6$ studies, 1206 participants; moderate-quality evidence) or nausea (RR 0.95 , $99 \% \mathrm{Cl} 0.52$ to 1.73 ; 4 trials, 1034 participants; moderate-quality evidence). Overall, the studies were rated at low to unclear risk of bias due to information on each risk of bias domain not being available. We judged the overall quality of evidence (using the GRADE approach) as low to moderate due to potential attrition bias resulting from missing outcome data and imprecise results with wide confidence intervals.

\section{Authors' conclusions}

Gabapentin has efficacy as an add-on treatment in people with drug-resistant focal epilepsy. However, the trials reviewed were of relatively short duration and provide no evidence for the long-term efficacy of gabapentin beyond a three-month period. The results cannot be extrapolated to monotherapy or to people with other epilepsy types.

\section{PLAIN LANGUAGE SUMMARY}

\section{Gabapentin as an add-on for drug-resistant focal epilepsy}

\section{Background}

Epilepsy is a disorder where recurrent seizures are caused by abnormal electrical discharges from the brain. Evidence from randomised controlled trials (well-designed clinical trials in which people are allocated at random to test a specific drug, treatment or other intervention) are often used to examine how effective and safe antiepileptic medicines are in people who experience such seizures. This review included 12 studies and data from 2607 people with focal seizures (seizures that occur in just one part of the brain).

\section{Study characteristics}

Data from six of the studies were combined in the analysis. All the participants (including adults and children) were previously taking at least one antiepileptic medicine and all were continuing to have seizures. Either gabapentin (an antiepileptic medicine) or a placebo (a tablet that contains no medicine) was added to the medicine regimen.

\section{Key results}

The results showed that gabapentin effectively reduced seizures when used as an additional treatment. Compared to a placebo, gabapentin was almost twice as likely to reduce seizures by $50 \%$ or more. The most common side effects associated with gabapentin ware ataxia (poor co-ordination and unsteady gait), dizziness, fatigue and drowsiness.

\section{Quality of the evidence}

Overall the quality of evidence was low to moderate as information was not reported for all participants in some of the trials and some of the results were imprecise. Research is needed into the effects of the long-term use of gabapentin.

The evidence is current to 20 March 2018. 
SUMMARY OF FINDINGS

Summary of findings for the main comparison. Gabapentin versus placebo for people with drug-resistant focal epilepsy

Gabapentin versus placebo for people with drug-resistant focal epilepsy

Patient or population: people with drug-resistant focal epilepsy

Settings: outpatient

Intervention: gabapentin

Comparator: placebo

\begin{tabular}{|c|c|c|c|c|c|c|}
\hline \multirow[t]{3}{*}{ Outcomes } & \multicolumn{2}{|c|}{ 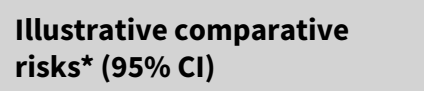 } & \multirow[t]{3}{*}{ Relative effect } & \multirow{3}{*}{$\begin{array}{l}\text { No of partici- } \\
\text { pants } \\
\text { (studies) }\end{array}$} & \multirow{3}{*}{$\begin{array}{l}\text { Quality of the } \\
\text { evidence } \\
\text { (GRADE) }\end{array}$} & \multirow[t]{3}{*}{ Comments } \\
\hline & Assumed risk & $\begin{array}{l}\text { Correspond- } \\
\text { ing risk }\end{array}$ & & & & \\
\hline & Placebo & Gabapentin & & & & \\
\hline $\begin{array}{l}\text { Reduction in seizure frequency of } \geq \\
\mathbf{5 0 \%} \text { : primary analysis } \\
\text { Number of seizures reported in seizure } \\
\text { diary }\end{array}$ & 12 per 100 & $\begin{array}{l}23 \text { per } 100 \\
\text { (17 to } 31)\end{array}$ & $\begin{array}{l}\text { RR } \mathbf{1 . 8 9} \\
(95 \% \mathrm{Cl} 1.40 \text { to } \\
2.55)\end{array}$ & $\begin{array}{l}1206 \\
\text { (6 studies) }\end{array}$ & $\begin{array}{l}\oplus \oplus \oplus \ominus \\
\text { Moderate }^{a}\end{array}$ & $\begin{array}{l}\mathrm{RR}>1 \text { indicated outcome was more } \\
\text { likely in gabapentin group. }\end{array}$ \\
\hline \multicolumn{7}{|l|}{ Follow-up: 12 to 14 weeks } \\
\hline $\begin{array}{l}\text { Treatment withdrawal } \\
\text { Number of participants withdrawn for } \\
\text { any reason }\end{array}$ & 10 per 100 & $\begin{array}{l}11 \text { per } 100 \\
\text { (8 to } 15)\end{array}$ & $\begin{array}{l}\text { RR } \mathbf{1 . 0 5} \\
(95 \% \mathrm{Cl} 0.74 \text { to } \\
1.49)\end{array}$ & $\begin{array}{l}1206 \\
\text { (6 studies) }\end{array}$ & $\begin{array}{l}\oplus \oplus \oplus \ominus \\
\text { Moderate }^{a}\end{array}$ & $\begin{array}{l}\mathrm{RR}>1 \text { indicated outcome was more } \\
\text { likely in gabapentin group. }\end{array}$ \\
\hline \multicolumn{7}{|l|}{ Follow-up: 12 to 14 weeks } \\
\hline $\begin{array}{l}\text { Adverse effects: ataxia } \\
\text { Number of participants experiencing } \\
\text { ataxia }\end{array}$ & 5 per 100 & $\begin{array}{l}10 \text { per } 100 \\
(5 \text { to } 20)\end{array}$ & $\begin{array}{l}\text { RR } 2.01 \\
(99 \% \mathrm{Cl} 0.98 \text { to } \\
4.11)\end{array}$ & $\begin{array}{l}787 \\
\text { (3 studies) }\end{array}$ & $\begin{array}{l}\oplus \oplus \ominus \ominus \\
\text { Lowb,c }\end{array}$ & $\begin{array}{l}\mathrm{RR}>1 \text { indicated outcome was more } \\
\text { likely in gabapentin group. }\end{array}$ \\
\hline \multicolumn{7}{|l|}{ Follow-up: 12 to 14 weeks } \\
\hline $\begin{array}{l}\text { Adverse effects: dizziness } \\
\text { Number of participants experiencing } \\
\text { dizziness }\end{array}$ & 6 per 100 & $\begin{array}{l}14 \text { per } 100 \\
\text { (8 to } 23)\end{array}$ & $\begin{array}{l}\text { RR } 2.43 \\
(99 \% \mathrm{Cl} 1.44 \text { to } \\
4.12)\end{array}$ & $\begin{array}{l}1206 \\
\text { (6 studies) }\end{array}$ & $\begin{array}{l}\oplus \oplus \oplus \ominus \\
\text { Moderate }^{a}\end{array}$ & $\begin{array}{l}\mathrm{RR}>1 \text { indicated outcome was more } \\
\text { likely in gabapentin group. }\end{array}$ \\
\hline
\end{tabular}


Follow-up: 12 to 14 weeks

Adverse effects: fatigue

4 per $100 \quad 7$ per 100

61

$\oplus \oplus \ominus \ominus$

$\mathrm{RR}>1$ indicated outcome was more

Number of participants experiencing fa-

tigue

(3 to 13)

(99\% Cl

(5 studies)

Low ${ }^{a, d}$

likely in gabapentin group.

Follow-up: 12 to 14 weeks

\section{Adverse effects: nausea}

experiencing

3.82

Number of participants experiencing

nausea

7 per 100

7 per 100

RR 0.95

1034

(99\% $\mathrm{Cl} 0.52$ to $\quad$ (4 studies)

$\oplus \oplus \oplus \ominus$

RR $>1$ indicated outcome was more

Follow-up: 12 to 14 weeks

\section{Adverse effects: somnolence}

Number of participants experiencing

(4 to 12 )

1.73)

Moderate $^{a}$

likely in gabapentin group.

somnolence

7 per $100 \quad 14$ per 100

RR 1.93

RR $1.93 \quad 1206$

1206

$\oplus \oplus \oplus \ominus$

$\mathrm{RR}>1$ indicated outcome was more

3.06)

Follow-up: 12 to 14 weeks

\section{Adverse effects: headache}

Number of participants experiencing

headache

(9 to 23)

(6 studies)

Moderate $^{a}$

likely in gabapentin group.

Follow-up: 12 to 14 weeks

*The basis for the assumed risk (e.g. the median control group risk across studies) is provided in footnotes. The corresponding risk (and its $95 \%$ confidence interval) is based on the assumed risk in the comparison group and the relative effect of the intervention (and its $95 \% \mathrm{Cl}$ ).

Cl: confidence interval; RR: risk ratio.

GRADE Working Group grades of evidence

High quality: further research is very unlikely to change our confidence in the estimate of effect.

Moderate quality: further research is likely to have an important impact on our confidence in the estimate of effect and may change the estimate.

Low quality: further research is very likely to have an important impact on our confidence in the estimate of effect and is likely to change the estimate.

Very low quality: we are very uncertain about the estimate.

aDowngraded once for risk of bias: four studies had missing data and did not carry out intention-to-treat analysis. Best-case and worst-case scenario analysis demonstrates that missing data may have impacted on the size of the true treatment effect

bDowngraded once for risk of bias: three studies had missing data and did not carry out intention-to-treat analysis.

cDowngraded once for imprecision: one study with small number of effects and wide confidence intervals; concern regarding the confidence in overall effect.

dDowngraded once for imprecision: two studies with small-study effects and wide confidence intervals; concern regarding the confidence in overall effect. 


\section{B A C K G R O U N D}

This is an updated version of the Cochrane Review previously published in 2013 (Al-Bachari 2013).

The purpose of this updated Cochrane Review was to summarise the current understanding of the role of gabapentin as an addon treatment in focal epilepsy resistant to at least one other antiepileptic drug (AED).

\section{Description of the condition}

Epilepsy is a common neurological disorder characterised by recurrent seizures. Most people given a diagnosis of epilepsy have a good prognosis and their seizures will be controlled by treatment with a single AED (Reynolds 1981). However, up to $30 \%$ will continue to have seizures despite treatment with adequate doses of AEDs, often requiring treatment with a combination (Cockerell 1995). These people represent a significant therapeutic problem taking into account that up to $2 \%$ to $3 \%$ of the population will experience epilepsy at some time in their lives (Hauser 1993).There is no internationally accepted definition of drug resistance, so for the purpose of this review, we considered people drug-resistant if they had focal-onset seizures (simple focal or complex focal or secondary generalised tonic-clonic seizures, or a combination of these) and failed to respond to at least one monotherapy AED.

\section{Description of the intervention}

Although more than 12 new AEDs have entered the market since 1993, up to $30 \%$ of people remain refractory to current treatments. Thus, a concerted effort continues to identify and develop new therapies that will help these people (Barker-Haliski 2014). Pharmacological treatment remains the first choice for controlling epilepsy (Loscher 2002), although recent decades have seen advances in vagal stimulation (Panebianco 2015), and surgery (West 2015). Current first-line treatment for focal epilepsy includes: lamotrigine, sodium valproate, carbamazepine, oxcarbazepine and levetiracetam. When first-line medications fail to achieve seizure freedom, add-on therapy is required.

\section{How the intervention might work}

Gabapentin was licensed for add-on use in the UK in 1993. The mechanism of action of gabapentin is uncertain (McClean 1995). Gabapentin is a structural analogue of the neurotransmitter gamma-aminobutyric acid (GABA). However, it does cross the blood brain barrier and its activities are believed not to be GABA-related. Gabapentin has a high volume of distribution, is not significantly protein-bound or metabolised, and does not induce or inhibit hepatic enzymes; thus, it has minimal-to-no known interactions with other AEDs.

\section{Why it is important to do this review}

In this review, we summarised evidence from randomised controlled trials (RCTs) on the efficacy and tolerability of gabapentin for people with drug-resistant focal epilepsy in order to aid clinical decision-making when considering gabapentin as an add-on treatment within this population.

\section{METHODS}

\section{Criteria for considering studies for this review} Types of studies

To be included in our review, studies had to meet all the following criteria:

1. RCTs that used an adequate method of concealment of randomisation (e.g. allocation of sequentially sealed packages of medication, sealed opaque envelopes, telephone randomisation);

2. double-blind trials, in which both participant and clinician treating or assessing outcome were blinded to treatment allocated;

3. placebo-controlled or alternative AED or range of gabapentin doses used as controls;

4. parallel-group or cross-over studies.

\section{Types of participants}

People of any age with drug-resistant focal epilepsy (i.e. experiencing simple focal, complex focal or secondary generalised tonic-clonic seizures).

\section{Types of interventions}

1. The active treatment group received gabapentin in addition to conventional AED.

2. The control group received matched placebo, different dose of gabapentin or alternative AED in addition to conventional AED.

\section{Types of outcome measures}

\section{Primary outcomes}

\section{Reduction in seizure frequency of $50 \%$ or more}

We chose the proportion of people with a $50 \%$ or greater reduction in seizure frequency in the treatment period compared to the prerandomisation baseline period as the primary outcome. This is commonly reported in this type of study and can be calculated for studies that do not report it from baseline seizure data.

\section{Seizure freedom}

The proportion of people with complete cessation of seizures during the treatment period.

\section{Secondary outcomes}

\section{Treatment withdrawal}

We used the proportion of people having treatment withdrawn during the treatment period as a measure of global effectiveness. Treatment is likely to be withdrawn due to adverse effects, lack of efficacy or a combination of both, and this is an outcome to which the person makes a direct contribution. In trials of short duration, it is likely that adverse effects will be the most common reason for withdrawal.

\section{O B JE C T IVES}

To evaluate the efficacy and tolerability of gabapentin when used as an add-on treatment for people with drug-resistant focal epilepsy. 


\section{Adverse effects}

1. The proportion of people experiencing the following five common and important adverse effects:
a. ataxia;
b. dizziness;
c. fatigue;
d. nausea;
e. somnolence.

2. The proportion of people experiencing the five most common adverse effects if different from a. to e. above.

\section{Search methods for identification of studies}

\section{Electronic searches}

Searches were run for the original review in 1998 and subsequent searches were run in 2000, 2003, 2005, 2007, 2010, 2011, 2012, 2013, 2015, 2016 and March 2018. For the latest update, we searched the following databases:

1. Cochrane Register of Studies (CRS Web, 20 March 2018), which includes the Cochrane Epilepsy Group's Specialized Register and the Cochrane Central Register of Controlled Trials (CENTRAL), using the strategy shown in Appendix 1;

2. MEDLINE (Ovid, 1946 to 20 March 2018) using the strategy shown in Appendix 2;

3. ClinicalTrials.gov (20 March 2018) using the strategy shown in Appendix 3;

4. World Health Organization International Clinical Trials Registry Platform (ICTRP, 20 March 2018) using the strategy shown in Appendix 4.

There were no language restrictions.

\section{Searching other resources}

We reviewed the reference lists of included studies to search for additional reports of relevant studies.

\section{Data collection and analysis}

\section{Selection of studies}

In the present update, two review authors ( $A C$ and MP) independently assessed trials for inclusion. Any disagreements were resolved by discussion; failing this, we sought an opinion from a third author.

\section{Data extraction and management}

Two review authors (AC and MP) independently extracted the following information for each trial using a data extraction sheet. Any discrepancies between the extractions of the two review authors were resolved by discussion.

\section{Methodological/trial design}

1. Method of randomisation and allocation concealment.

2. Method of double-blinding.

3. Whether any participants had been excluded from reported analyses.

4. Duration of baseline period.

5. Duration of treatment period.
6. Dose(s) of gabapentin tested.

\section{Participant/demographic information}

1. Total number of participants allocated to each treatment group.

2. Age/sex.

3. Number with focal/secondary generalised seizures.

4. Seizure types.

5. Seizure frequency during the baseline period.

6. Number of background drugs.

Parke Davis sponsored most trials; we asked them to confirm the following information:

1. method of randomisation;

2. total number randomised to each group;

3. number of participants in each group achieving a 50\% or greater reduction in seizure frequency per treatment group;

4. number of participants having treatment withdrawn postrandomisation per treatment group;

5. for those excluded:

a. the reason for exclusion;

b. whether any of those excluded completed the treatment phase;

c. whether any of those excluded had a $50 \%$ or greater reduction in seizure frequency during the treatment phase.

\section{Outcomes}

We recorded the number of participants experiencing each outcome (see Types of outcome measures) per randomised group.

We contacted authors of trials for any missing information.

\section{Assessment of risk of bias in included studies}

Two review authors (AC and MP) independently assessed the risk of bias for each trial using the Cochrane 'Risk of bias' tool as described in the Cochrane Handbook for Systematic Reviews of Interventions Higgins 2011. We rated included studies as high risk, low risk, or unclear risk on six domains applicable to RCTs: randomisation method, allocation concealment, blinding methods, incomplete outcome data, selective outcome reporting and other sources of bias.

We outlined studies failing to meet the criteria to be included in the meta-analysis in narrative form; statistics for those included in the meta-analysis are outlined below.

\section{Measures of treatment effect}

We presented the outcomes as risk ratios (RR) with $95 \%$ or $99 \%$ confidence intervals $(\mathrm{Cl})$.

\section{Unit of analysis issues}

We assessed cross-over studies to determine if they presented suitable data to allow for inclusion in meta-analysis using either 'paired' results adjusted for the cross-over design, or first period results.

One cross-over trial did not provide suitable data for inclusion in the meta-analysis, but was discussed in narrative form (Leach 1997). 


\section{Dealing with missing data}

We sought any missing data from study authors. We carried out intention-to-treat (ITT), best-case and worst-case analysis to account for any missing data (see Data synthesis).

\section{Assessment of heterogeneity}

We assessed clinical heterogeneity by comparing the distribution of important participant factors among trials (e.g. age, seizure type, duration of epilepsy) and trial factors (e.g. methods of randomisation and blinding, missing data). We examined statistical heterogeneity using a Chi2 test $(P>0.10)$ and the 12 statistic (Higgins 2011).

\section{Assessment of reporting biases}

\section{Protocol versus full study}

We requested all protocols from study authors to enable a comparison of outcomes of interest. We intended to investigate any suspected outcome reporting bias using the ORBIT matrix system (Kirkham 2010).

\section{Funnel plot}

Reporting biases arise when dissemination of research findings is influenced by the nature and direction of results (Higgins 2011). We intended to use funnel plots for investigating reporting biases when 10 or more studies were included in meta-analysis, with awareness that they have limited power to detect small-study effects and we planned to seek statistical advice on their interpretation.

For this review, we did not produce funnel plots for outcomes as fewer than 10 studies were included in meta-analysis.

\section{Data synthesis}

We employed a fixed-effect meta-analysis to synthesise the data. Comparisons we carried out included:

1. intervention group versus controls on seizure reduction;

2. intervention group versus controls on seizure freedom;

3. intervention group versus controls on treatment withdrawal;

4. intervention group versus controls on adverse effects.

We performed separate comparisons for different types of control group (i.e. placebo or active control group) and study characteristics (i.e. cross-over designed trials) to ensure appropriate combination of data.

The preferred estimate was the Mantel-Haenszel RR. For the outcomes reduction in seizure frequency of $50 \%$ of more and treatment withdrawal, we used $95 \%$ confidence intervals (Cls). For individual adverse effects we used $99 \%$ Cls to make an allowance for multiple testing by using wider Cls. This is not a strict formal adjustment, as the number of individual adverse effects is not known in advance.

Our analyses included all participants in the treatment group to which they had been allocated. For the primary efficacy outcome (reduction in seizure frequency of $50 \%$ or more, we undertook three analyses.

1. Primary (ITT) analysis: participants not completing follow-up or with inadequate seizure data were assumed to be non- responders. To test the effect of this assumption, we undertook the following sensitivity analyses:

a. worst-case analysis: participants not completing follow-up or with inadequate seizure data were assumed to be nonresponders in the gabapentin group and responders in the placebo group;

b. best-case analysis: participants not completing follow-up or with inadequate seizure data were assumed to be responders in the gabapentin group and non-responders in the placebo group.

\section{Dose regression analysis}

We examined dose-response relationships using logistic regression (for the five adult trials) and calculated probabilities for the following for differing doses: the percentage of participants having a 50\% response; and the difference in the percentage of participants responding to each dose compared to placebo. A binary variable was defined with value 0 if the response was less than $50 \%$ and value 1 otherwise. We examined doseresponse relationships using logistic regression, in the framework of generalised linear models, using the package GLIM, with this binary variable as the outcome variable (McCullagh 1989). Trial effects (i.e. adjustment for trial specific differences) were not included in the regression models as it was generally not possible to do so as some doses are confounded with trials; in other words, the dose was evaluated in only a single trial. As none of the tests for heterogeneity reached a significance level of less than $30 \%$, it seemed reasonable to proceed without trial effects.

\section{Subgroup analysis and investigation of heterogeneity}

We intended to investigate heterogeneity using subgroup analysis of important participant factors among trials (e.g. age, seizure type, duration of epilepsy if deemed appropriate. As no important heterogeneity was identified in the meta-analyses in this review, no subgroup analysis was conducted.

\section{Sensitivity analysis}

We intended to carry out sensitivity analysis if there were peculiarities between study quality, characteristics of participants, interventions and outcomes.

\section{Summarising and interpreting results}

We used the GRADE approach, as outlined in the GRADE Handbook (Schünemann 2013), to interpret findings, and GRADEpro GDT software (which imports data from Review Manager 5 software (GRADEpro GDT 2015)), to create a 'Summary of findings' table for the primary outcome (reduction in seizure frequency of $50 \%$ or more) and secondary outcomes (treatment withdrawal and adverse effects).

We created a 'Summary of findings' table for the most important comparison (gabapentin versus placebo). We did not create 'Summary of findings' tables for other comparisons with only a single study contributing to the comparison. 


\section{RESULTS}

\section{Description of studies}

\section{Results of the search}

Updated searches conducted since 2013 revealed 107 records identified from the databases outlined in Electronic searches.
After removal of 15 duplicates, 92 records and were screened for inclusion in the review. We excluded 84 clearly irrelevant records and assessed eight full-text articles for eligibility. We identified one new study in this review update (French 2016) but did not include it in the meta-analyses as no other included studies compared the AEDs considered in this study (see Figure 1). 
Figure 1. Study flow diagram. Date of search 20 March 2018. RCT: randomised controlled trial.

11 studies included in previous update: 5 studies included in narrative synthesis; 6 studies included in quantitative synthesis (meta-analyses)
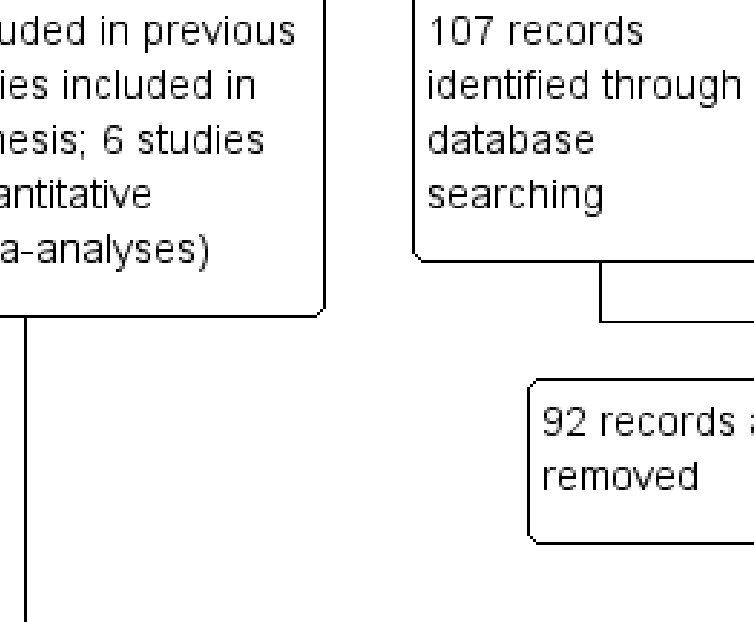


\section{Included studies}

Overall, the review included 12 studies, six of which were in the meta-analyses. The data from the six remaining studies were not combined in meta-analyses due to the differences in comparisons investigated.

Kwan 2000 and Shapiro 2000 papers are awaiting classification as only abstracts were obtainable, therefore, it was not possible to critique the study design (see Characteristics of studies awaiting classification).

There were seven trials that compared gabapentin to a placebo (Anhut 1994; Appleton 1999; Leach 1997; Sivenius 1991; UK Gabapentin 1990; US Gabapentin 1993; Yamauchi 2006), two trials that examined two different doses of gabapentin (Fisher 2001; Tomovic 1999), one trial that compared gabapentin to vigabatrin (Lindberger 2000), one trial that compared gabapentin to lamotrigine (Sethi 2002), and one trial that compared gabapentin to pregabalin (French 2016). All participants had drug-resistant focal epilepsy and were taking at least one monotherapy AED. Pre-existing AED regimens remained unchanged throughout the study period. All outcome measures included seizure reduction and adverse effects.

One parallel trial had a 12-week pre-randomisation baseline period and a 12-week treatment period of gabapentin $900 \mathrm{mg} /$ day (111 participants) or gabapentin $1200 \mathrm{mg} /$ day (52 participants) or placebo (109 participants) (Anhut 1994). Study medication was administered three times daily (TDS). Included participants had a minimum of six focal seizures within the baseline period and were aged 12 years or over. Women of childbearing potential on adequate contraception and participants with additional seizure types were also included in this study.

One multicentre parallel trial had three phases: six weeks of baseline period, nine weeks of double-blind dose escalation phase and 12 weeks of double-blind maintenance phase (French 2016). There were two arms: 242 participants randomised to gabapentin (300 mg/day, $600 \mathrm{mg} /$ day, $1200 \mathrm{mg} /$ day, $1500 \mathrm{mg} /$ day and $1800 \mathrm{mg} /$ day) and 242 participants randomised to active control (pregabalin $150 \mathrm{mg} /$ day, $300 \mathrm{mg} /$ day, $450 \mathrm{mg} /$ day and 600 $\mathrm{mg} /$ day), but 482 participants (241 in gabapentin group and 241 in pregabalin group) received intended treatment. Participants were adults aged 18 to 80 years. During the nine-week dose-escalation phase, the minimum maintenance phase dose was gabapentin $1200 \mathrm{mg} /$ day and pregabalin $300 \mathrm{mg} /$ day TDS. During the 21week double-blind phase of the study, the median doses were gabapentin $1500 \mathrm{mg} /$ day and pregabalin $450 \mathrm{mg} /$ day.

The baseline period in one parallel trial was six weeks with a treatment period of 12 weeks (Appleton 1999). Gabapentin $600 \mathrm{mg} /$ day to $1200 \mathrm{mg} /$ day was administered TDS and was dependent on the weight of the participant. One hundred and twentyeight participants received placebo and 119 participants received gabapentin. Participants were children aged less than 12 years and with a minimum of four seizures during the baseline period.

One cross-over trial was a placebo-controlled study that did not have a pre-randomisation baseline period; however, all participants reported at least four seizures per month for the previous three months (Leach 1997). There were four treatment arms (gabapentin $1200 \mathrm{mg} /$ day, $1800 \mathrm{mg} /$ day and $2400 \mathrm{mg} /$ day, and placebo each administered on a TDS basis). All participants received all doses/placebo in a cross-over design with a fourweek washout period between each treatment period. The study recruited 27 participants and analysed 23 participants.

One parallel trial had a baseline period of three months in which adults with focal epilepsy experienced four or more seizures a month (Sivenius 1991). Participants received either gabapentin $900 \mathrm{mg} /$ day (16 participants), gabapentin $1200 \mathrm{mg} /$ day (nine participants) or placebo (18 participants). Treatment medication was administered for 3 months.

One parallel trial had a three-month baseline period where participants had at least one focal seizure per week (UK Gabapentin 1990). This study had a two-week initiation phase of gabapentin 600 $\mathrm{mg} /$ day or placebo administered TDS, after which 61 participants began a 12-week treatment period of $1200 \mathrm{mg} /$ day taken TDS and 66 participants received placebo.

One parallel trial recruited 306 adults, randomising 53 participants to gabapentin $600 \mathrm{mg} /$ day, 101 participants to gabapentin 1200 $\mathrm{mg}$ /day, 54 participants to gabapentin $1800 \mathrm{mg} /$ day and 98 participants to placebo, all administered TDS for 12 weeks (US Gabapentin 1993). The study implemented an initiation period of two to three days of either gabapentin $300 \mathrm{mg} /$ day or $600 \mathrm{mg} /$ day up to the required dose. The baseline period was three months and included people who had a minimum of four focal seizures per month.

One trial examining gabapentin versus placebo had a baseline period of 12 weeks and included people who had a minimum of eight focal seizures during baseline (Yamauchi 2006). Adults were randomised into one of three treatment arms: gabapentin $1200 \mathrm{mg} /$ day (86 participants), gabapentin $1800 \mathrm{mg} /$ day (41 participants) and placebo ( 82 participants), taken TDS over 12 weeks.

Two RCTs were gabapentin dose trials that had no placebo group (Fisher 2001; Tomovic 1999). Fisher 2001 compared slow initiation (300 mg on day one, $600 \mathrm{mg}$ on day two and then $900 \mathrm{mg} /$ day for five days) and rapid initiation of gabapentin (placebo for the first two days followed by $900 \mathrm{mg} /$ day for five days). Three hundred and sixty participants were in the slow initiation group and 360 participants were in the rapid initiation dose. There was no baseline period; participants were required to have been taking at least one AED for one month prior to the study and were considered to have inadequate seizure control as defined by the authors. Participants were aged 12 years or older. The trial period was seven days. Tomovic 1999 compared gabapentin $900 \mathrm{mg} /$ day versus gabapentin $1200 \mathrm{mg} /$ day administered TDS over 12 weeks. There were nine participants in each group. There was no formal baseline period; participants were considered to have unsatisfactorily controlled seizures while taking at least one firstline AED for three months prior to the study, as defined by the authors.

One trial compared gabapentin to lamotrigine; it had an eightweek baseline period (Lindberger 2000). All participants had tried no more than two AED monotherapy regimens and were on one AED at the time of study (this had to exclude phenytoin). The study required a minimum seizure frequency of four seizures during an eight-week baseline period and two or more seizures during the last month. One hundred and two participants (aged 12 to 75 years) received either gabapentin or vigabatrin add-on treatment. 
There was a flexible dosing regimen over the subsequent 24 weeks: gabapentin variable dose $1800 \mathrm{mg} /$ day minimum, then $2400 \mathrm{mg} /$ day and then a maximum of $3600 \mathrm{mg} /$ day, increased every eight weeks as tolerated. The vigabatrin initial dose was $1000 \mathrm{mg} /$ day, then $2000 \mathrm{mg} /$ day, then $4000 \mathrm{mg} /$ day, increased in the same manner (as tolerated by adverse effects) and increased if complete seizure freedom was not attained. The total trial period was 24 weeks; however, outcome measures were taken at eight weeks (awaiting clarification from author).

One trial compared gabapentin to lamotrigine in participants refractory to the maximum tolerated dose of carbamazepine monotherapy, with a seizure duration of two years or less (Sethi 2002). Twenty-seven participants received gabapentin and 25 participants received lamotrigine and were aged 10 to 60 years. Baseline seizure frequency was at least four seizures despite treatment (unclear over what time frame). The baseline period was time of enrolment. The trial period was 12 weeks. Treatment was gabapentin $300 \mathrm{mg}$ on day one, $300 \mathrm{mg}$ twice daily on day two and thereafter an increment of $300 \mathrm{mg} /$ day until seizures were controlled or toxic effects appeared. Lamotrigine was started at 50 $\mathrm{mg} /$ day for two weeks, then $50 \mathrm{mg}$ twice daily for two weeks, then increased by $50 \mathrm{mg}$ to $100 \mathrm{mg}$ every two weeks until seizures were controlled or there were toxic effects.
For further information on each trial, see the Characteristics of included studies table.

\section{Excluded studies}

In this update, we excluded eight studies for the following reasons: three were not RCTs (Arya 2013; Bodalia 2013; Ohtsuka 2014); two did not enrol an eligible population (Jacoby 2015; Nonoda 2014); two studies did not include gabapentin as an add-on treatment (Korean Gabapentin Study Group 2000; Semah 2014); and one had no seizure data recorded (Crawford 1987).

The details of these studies are given in the Characteristics of excluded studies table.

\section{Risk of bias in included studies}

See Figure 2 and Figure 3 for a summary of the 'Risk of bias' in each included study. We rated included studies as having low, high or unclear risk of bias for six domains applicable to RCTs: randomisation method, allocation concealment, blinding methods, incomplete outcome data, selective outcome reporting and other sources of bias.

\section{Figure 2. Risk of bias graph: review authors' judgements about each risk of bias item presented as percentages} across all included studies.

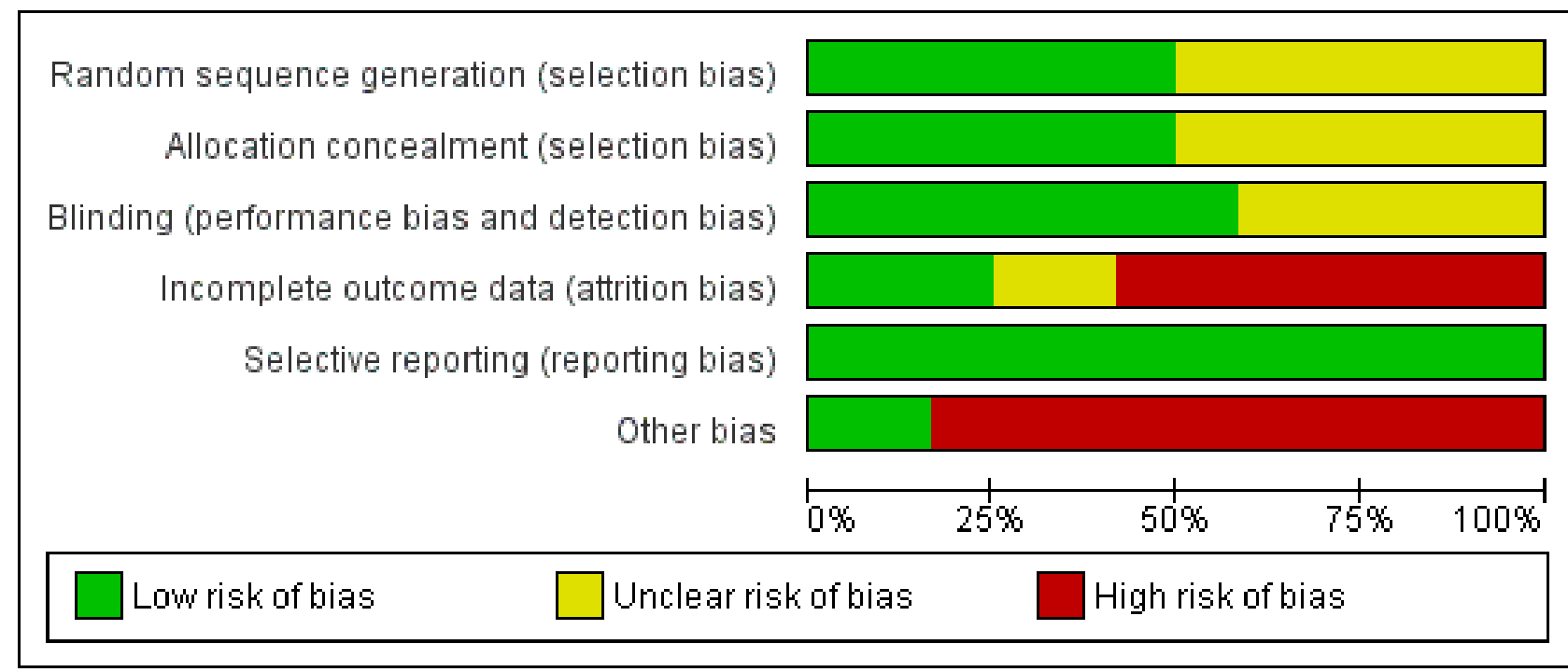


Figure 3. Risk of bias summary: review authors' judgements about each risk of bias item for each included study.

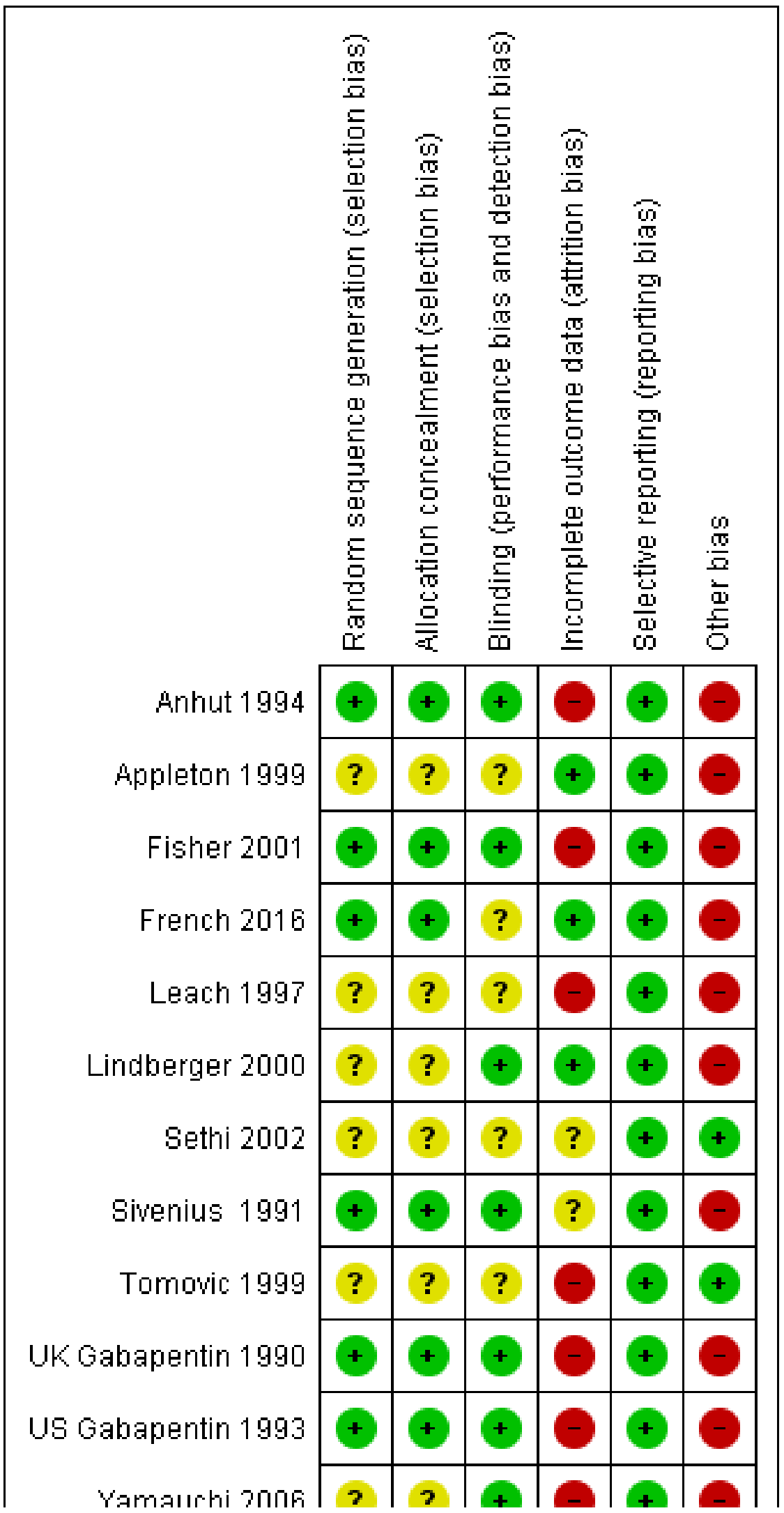


Figure 3. (Continued)

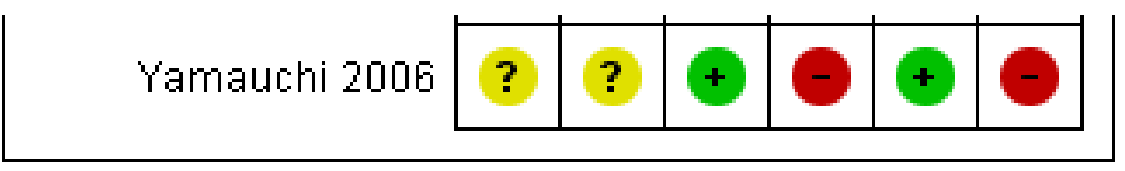

\section{Allocation}

Six studies did not describe the method of allocation concealment (authors have been contacted but we have been unable to clarify) and therefore we rated these as unclear in terms of bias (Appleton 1999; Leach 1997; Lindberger 2000; Sethi 2002; Tomovic 1999; Yamauchi 2006). The other six studies achieved randomisation by generating random lists using random permuted blocks and by computer-generated randomisation; and concealed allocation by dispensing sequentially numbered packages to each participant allocated treatment; we rated these studies as low risk of bias (Anhut 1994; Fisher 2001; French 2016; Sivenius 1991; UK Gabapentin 1990; US Gabapentin 1993).

\section{Blinding}

In six studies, the means of blinding was unclear (Appleton 1999; French 2016; Leach 1997; Sethi 2002; Tomovic 1999; Yamauchi 2006); there were no specific details regarding who was blinded (i.e. participants, study personnel or outcome assessors). The remaining six studies achieved blinding by providing packaging and tablets that were identical in appearance for the gabapentin and placebo groups; and were at low risk of bias for this domain (Anhut 1994; Fisher 2001; Lindberger 2000; Sivenius 1991; UK Gabapentin 1990; US Gabapentin 1993).

\section{Incomplete outcome data}

We rated three studies as low risk of bias for attrition bias due to the ITT analyses undertaken by the study authors (Appleton 1999; French 2016; Lindberger 2000). Seven studies excluded participants from the study and analysis without providing reasons for this; and therefore we rated these as high in terms of bias (Anhut 1994; Fisher 2001; Leach 1997; Tomovic 1999; UK Gabapentin 1990; US Gabapentin 1993; Yamauchi 2006). Two studies analysed results on an 'as treated' basis, but did report attrition; and were at unclear risk of bias for this domain (Sethi 2002; Sivenius 1991).

\section{Selective reporting}

We rated all included studies at low risk of bias for this domain as there was no suspicion of selective outcome reporting bias: all expected outcomes were reported in each of the publications. .

\section{Other potential sources of bias}

All trials included in this review were sponsored by Parke Davis, the manufacturers of gabapentin, apart from Sethi 2002 and Tomovic 1999, and therefore, we rated all studies as having a high risk of funding bias, but Sethi 2002 and Tomovic 1999 studies as having a low risk for this domain. There was no evidence of further bias in any of the included studies.

\section{Effects of interventions}

See: Summary of findings for the main comparison Gabapentin versus placebo for people with drug-resistant focal epilepsy

\section{Gabapentin versus placebo}

Seven trials compared gabapentin to a placebo (Anhut 1994; Appleton 1999; Leach 1997; Sivenius 1991; UK Gabapentin 1990; US Gabapentin 1993; Yamauchi 2006).

\section{Reduction in seizure frequency of $50 \%$ or more}

Given that all participants had drug-resistant focal epilepsy, it seemed reasonable to combine results from the paediatric and adult studies for an overall estimate (irrespective of dose). Data from the paediatric study (Appleton 1999) could not be included in dose regression models, as participants were not randomised to a specific daily dose. Seven trials provided data for this outcome (Anhut 1994; Appleton 1999; Leach 1997; Sivenius 1991; UK Gabapentin 1990; US Gabapentin 1993; Yamauchi 2006). See Figure 4 for forest plots. One trial was not suitable for inclusion in the meta-analysis due to the cross-over design but was discussed in narrative form below (Leach 1997). 
Figure 4. Forest plot of comparison: 1 Gabapentin versus placebo, outcome: 1.1 Reduction in seizure frequency $\geq$ $50 \%$.

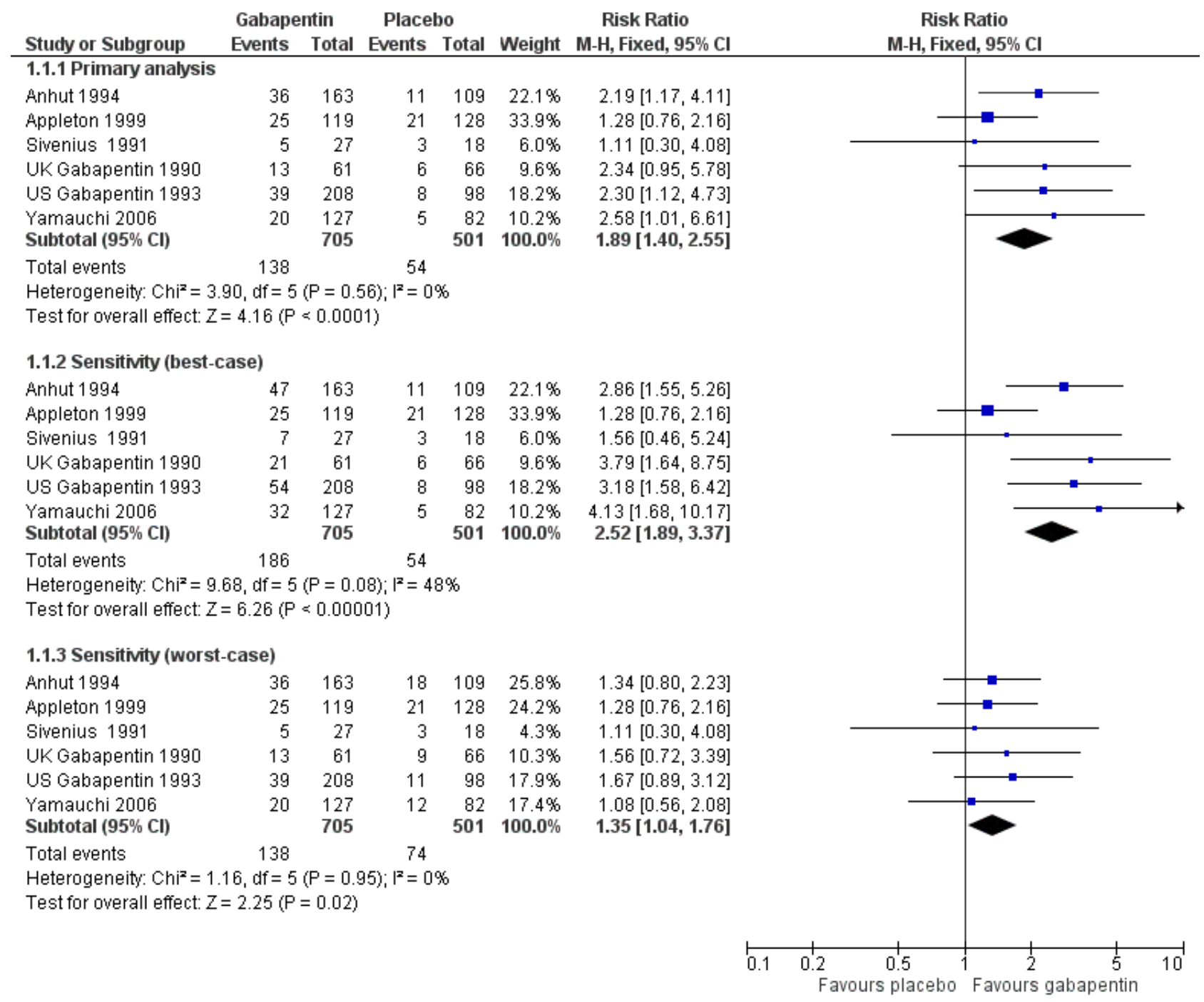

\section{Intention-to-treat analysis}

An analysis pooling data from six studies showed no evidence of heterogeneity $\left(\mathrm{Chi}^{2}=3.90, \mathrm{P}=0.56, \mathrm{I}^{2}=0 \%\right)$. The overall RR for reduction in seizure frequency of $50 \%$ or more was $1.89(95 \% \mathrm{Cl} 1.40$ to $2.55 ; 1206$ participants; moderate-quality evidence, Analysis 1.1).

\section{Best-case and worst-case scenarios}

$\mathrm{Chi}^{2}$ tests for heterogeneity for a response to gabapentin indicated no significant heterogeneity (best-case: $P=0.08$; worst-case: $P=$ 0.95). The overall RRs for $50 \%$ responders across all studies were $2.52(95 \% \mathrm{Cl} 1.89$ to 3.37$)$ for best-case scenarios and $1.35(95 \% \mathrm{Cl}$ 1.04 to 1.76 ) for worst-case scenarios (Analysis 1.1).

For all three analyses, the results suggested a significant treatment effect. However, there was a considerable difference between estimates.

\section{Dose-response regression}

Intention-to-treat analysis

A linear dose-response model gave a good summary (for the five adult trials) of the log odds of $50 \%$ response rate. After adjusting for dose, there was no difference in estimated dose-response between studies. The log odds of response increase by 0.19 (standard error of the mean (SEM) 0.045) for a $300 \mathrm{mg}$ increase in daily gabapentin dose. This is about a $20 \%$ increase in the odds of response with a 300 $\mathrm{mg}$ increase in gabapentin dose. The reduction in deviance due to dose was 19.1 on one degree of freedom, and the residual deviance was 10.9 on 13 degrees of freedom. The trial in children was not included, as the doses were prescribed to achieve particular levels of milligrams per kilogram per day.

The results were summarised in the following tables:

- the estimated percentage of participants responding to each gabapentin dose and the percentage difference in participants responding to each gabapentin dose compared to placebo with 95\% Cl (ITT) (Table 1); 
- the estimated percentage of participants responding to each gabapentin dose and the percentage difference in participants responding to each gabapentin dose compared to placebo with 95\% Cl (best-case) (Table 2);

- the estimated percentage of participants responding to each gabapentin dose and the percentage difference in participants responding to each gabapentin dose compared to placebo with 95\% Cl (worst-case) (Table 3);

In the best-case analysis, there was about a 30\% increase in the odds of response with a $300 \mathrm{mg}$ increase in gabapentin dose and in the worst-case analysis, there was about a $10 \%$ increase in the odds of response with a $300 \mathrm{mg}$ increase in gabapentin dose.

All three analyses (ITT, best-case and worst-case) showed a significant increase in therapeutic effect with increasing dose. However, there was a striking difference in the proportion of responders estimated.

\section{Seizure freedom}

Only two trials comparing gabapentin to placebo reported seizure freedom data (Appleton 1999; Yamauchi 2006).

Yamauchi 2006 reported no participants attaining seizure freedom, whereas Appleton 1999 reported 3/119 participants receiving gabapentin as seizure-free compared to $1 / 128$ participants receiving placebo. Due to the very small numbers of participants achieving seizure freedom in the two trials, the data is not combined in meta-analysis

\section{Treatment withdrawal}

A Chi ${ }^{2}$ test of heterogeneity suggested no significant statistical heterogeneity $\left(\mathrm{Chi}^{2}=4.13, \mathrm{df}=4, \mathrm{P}=0.53, \mathrm{I}^{2}=0 \%\right)$. The overall RR for withdrawal for any reason was $1.05(95 \% \mathrm{Cl} 0.74$ to $1.49 ; 1206$ participants; moderate-quality evidence, Analysis 1.2), hence there was insufficient evidence to conclude that people were more likely to withdraw from gabapentin than placebo, but there could have been a substantial withdrawal rate.

\section{Adverse effects}

In addition to reports of ataxia, dizziness, fatigue, nausea and somnolence, headache was among the six most common adverse effects was included in our analysis. There were significant differences between gabapentin and placebo for the following adverse effects (see Analysis 1.3): ataxia (RR 2.01, $99 \% \mathrm{Cl} 0.98$ to 4.11; 3 RCTs; 787 participants; low-quality evidence); dizziness (RR 2.43, $99 \% \mathrm{Cl} 1.44$ to 4.12 ; 6 RCTs; 1206 participants; moderatequality evidence); fatigue (RR $1.95,99 \% \mathrm{Cl} 0.99$ to $3.82 ; 5 \mathrm{RCTs}$; 1161 participants; low-quality evidence) and somnolence (RR 1.93, $99 \% \mathrm{Cl} 1.22$ to 3.06 ; 6 RCTs, 1206 participants; moderate-quality evidence). There were no significant differences for headache (RR $0.79,99 \% \mathrm{Cl} 0.46$ to 1.35 ; 6 RCTs; 1206 participants; moderatequality evidence) or nausea (RR $0.95,99 \% \mathrm{Cl} 0.52$ to 1.73 ; 4 RCTs; 1034 participants; moderate-quality evidence).

\section{Cross-over trial, not included in meta-analysis}

One trial was not suitable for inclusion in the meta-analysis due to the cross-over design and due to a lack of a pre-randomisation baseline period and was discussed in narrative form (Leach 1997).

\section{Reduction in seizure frequency of $\mathbf{5 0 \%}$ or more and seizure freedom}

The cross-over trial evaluated 23/27 participants (although there were six withdrawals, two participants withdrew sufficiently late in the study to provide analysable data). Two participants achieved total seizure control throughout the active treatment phase and none in the placebo phase. For simple focal seizures, two participants showed 'in excess' of 50\% reduction in seizure frequency. The median monthly frequency for simple focal seizures was not significantly reduced in the treatment group $(P=$ $0.80)$. The study reported complex focal seizures with secondary generalisation separately; 5/17 participants had in excess of $50 \%$ reduction in seizure frequency (non-significant).

\section{Treatment withdrawal}

Six participants withdrew, five due to adverse effects (four while receiving placebo, one while receiving gabapentin) and one of whom withdrew consent to participate after the second visit. One participant did not provide complete data for seizure frequency and was withdrawn from the study.

\section{Adverse effects}

Nineteen (79\%) participants reported 47 adverse effects with gabapentin and 15 participants $(63 \%)$ reported 30 adverse effects with placebo. There was a statistically significant difference $(P=$ 0.006 ) at gabapentin $2400 \mathrm{mg} /$ day. The types of adverse effects were not reported.

\section{Dose comparison trials with no placebo group}

Two studies compared two dose regimens with no placebo (Fisher 2001; Tomovic 1999).

For one study, we sent a data extraction form to a translator (Tomovic 1999). Our understanding is that the study combined outcomes for the two treatment arms, thus a comparison between the two treatment groups could not be made. Another study only measured adverse effects at day two and day seven of a slow initiation regimen and a rapid initiation regimen; therefore, this is presented narratively below (Fisher 2001).

\section{Reduction in seizure frequency of $50 \%$ or more}

In the Tomovic 1999 study, 13/18 (72.2\%) participants experienced $50 \%$ or greater reduction in seizures (two of whom achieved a $100 \%$ reduction). Three participants had a $26 \%$ to $49 \%$ reduction in seizure frequency. Two participants had worse seizure control.

Fisher 2001 did not measure reduction in seizure frequency of $50 \%$ or more.

\section{Seizure freedom}

In the Tomovic 1999 studies 2/18 (11.1\%) participants were seizurefree during the treatment period; however, it was not reported in which dose group this was achieved.

Fisher 2001 did not measure seizure freedom.

\section{Treatment withdrawals}

Tomovic 1999 did not report any treatment withdrawals. 
Fisher 2001 reported only participants who had full exposure to the study medication during the whole period of assessment (i.e. details of withdrawals were not provided).

\section{Adverse effects}

Tomovic 1999 reported adverse effects in three participants, two of whom had dizziness and one had excessive sleepiness (they were excluded from the study, therefore, not included in the total number of participants). They also noted bulimia, tremor, diplopia, headache, nausea and ataxia.

Fisher 2001 reported adverse effects on day three and day seven of a slow and rapid initiation regimen of gabapentin. See Table 4 for the proportion of people with adverse effects with percentages. There were no statistically significant differences between the two dose regimens, apart from more dizziness in the rapid initiation group compared to the slow initiation group at day three only.

In addition, Tomovic 1999 reported 24-hour electroencephalogram (EEG) recordings pre- and postintervention and revealed a reduction in total epileptiform discharges from 229.87 to 167.13 .

\section{Gabapentin versus vigabatrin}

One study compared gabapentin versus vigabatrin (Lindberger 2000).

\section{Reduction in seizure frequency of $50 \%$ or more and seizure freedom}

The study noted a reduction in seizure frequency of $50 \%$ or more and seizure freedom in $27 / 50$ participants (54\%) in the gabapentin group and $34 / 52$ participants (56\%) in the vigabatrin group (on an ITT basis); the 95\% Cls were wide and this was not deemed statistically significant. The proportion of seizure-free participants without adverse effects was $13 / 50(26 \%)$ in the gabapentin group and $18 / 52(35 \%)$ participants in the vigabatrin group. This was not statistically significant. The study measured an extra variable of 'improvement rate' (proportion of participants with $50 \%$ or greater seizure reduction without adverse effects), which was $24 / 50(48 \%)$ participants in the gabapentin group and 29/52 (56\%) participants in the vigabatrin group. Thirteen out of 50 participants were seizure-free in the gabapentin group compared to $18 / 52$ participants in the vigabatrin group.

\section{Treatment withdrawals}

There were 14 withdrawals from the study as a result of adverse effects, seven in each group. In the gabapentin group they were status epilepticus, psychiatric problems, epigastric pain, diplopia, vertigo and dizziness (three participants); in the vigabatrin group they were depression, generalised seizure, rash, numbness and dizziness (three participants).

\section{Adverse effects}

In the gabapentin group, three participants experienced serious adverse effects which were status epilepticus, pyelonephritis and psychiatric problems. In the vigabatrin group, four participants had serious adverse effects, which were agitation, depression, weight gain, mononucleosis and a secondary generalised seizure. Thirtyeight $(76 \%)$ participants in the gabapentin group and $45(86.5 \%)$ participants in the vigabatrin group experienced adverse effects of any type. The five most common adverse effects were similar in both groups (tiredness, dizziness, respiratory infection, headache and diarrhoea). Specific proportions of individual adverse effects were not provided.

\section{Gabapentin versus lamotrigine}

One trial compared gabapentin versus lamotrigine (Sethi 2002).

\section{Reduction in seizure frequency of $50 \%$ or more and seizure freedom}

There was a $50 \%$ or greater reduction in seizure frequency by $77.7 \%$ of participants in the gabapentin group and $92 \%$ of participants in the lamotrigine group (ITT analysis). There was complete seizure control in $8 / 27$ (29.6\%) participants in the gabapentin group; this was not specified in the lamotrigine group.

\section{Treatment withdrawals}

Sethi 2002 did not report any treatment withdrawals.

\section{Adverse effects}

Twenty-two out of $27(81.5 \%)$ participants in the gabapentin group and $18 / 25(72 \%)$ participants in the lamotrigine group reported adverse effects. The most common adverse effects were neurotoxic: dizziness (gabapentin: 22.2\%; lamotrigine: $28 \%$ ), diplopia (gabapentin: $11.11 \%$; lamotrigine: $24 \%$ ), weakness (gabapentin: 14.8\%; lamotrigine: 24\%), headache (gabapentin: 25.9\%; lamotrigine: 20\%), drowsiness (gabapentin: 14.8\%; lamotrigine: 12\%), tiredness (gabapentin: 14.8\%; lamotrigine: 4\%), amnesia (gabapentin: 11.11\%; lamotrigine: 12\%), tingling sensation (gabapentin: $11.11 \%$; lamotrigine: $0 \%$ ) and anorexia (gabapentin: $11.11 \%$; lamotrigine: $8 \%$ ).

There were no serious adverse effects in the gabapentin group. In the lamotrigine group, there were two serious adverse effects (Steven Johnson's syndrome and anxiety neurosis (corresponding with an increase in seizure frequency)). There was an increase in the number of seizures in one participant receiving gabapentin 2400 $\mathrm{mg}$ /day. In the gabapentin group, there was a change of seizure type from focal seizures to myoclonic jerks or atypical seizures in five participants during treatment. In the lamotrigine group, seizure type changed to atypical absence (two participants) and pseudoseizures (two participants).

Additionally, the benefit of gabapentin was more pronounced in participants with simple focal seizures with secondary generalisation than in participants with simple and complex focal seizures without secondary generalisation, whereas all subtypes of epilepsy responded similarly in the lamotrigine group.

\section{Gabapentin versus pregabalin}

One study compared gabapentin versus pregabalin (French 2016).

\section{Reduction in seizure frequency of $50 \%$ or more and seizure freedom}

There was a reduction in seizure frequency of $50 \%$ or more in $140 / 240(58.3 \%)$ participants in the gabapentin group and $134 / 238$ (56.3\%) participants in the pregabalin groups (on an ITT basis); the $95 \%$ Cls were wide and this was not deemed statistically significant. The proportion of seizure-free participants was 62/182 (34.1\%) in the gabapentin group and 58/189 (30.7\%) in the pregabalin group; these were not statistically significant. The study measured an extra variable of 'improvement rate' (proportion of participants with 75\% 
or greater seizure reduction) and was $82 / 240$ (34.2\%) participants in the gabapentin group and $80 / 238(33.6 \%)$ participants in the pregabalin group.

\section{Treatment withdrawals}

There were 123 withdrawals for any reason from the study, and 31 due to adverse effects (16 in the gabapentin group and 15 in the pregabalin group). In the gabapentin group, the adverse effects were status epilepticus, psychiatric problems, epigastric pain, diplopia, vertigo and dizziness (three participants); in the vigabatrin group, they were depression, generalised seizure, rash, numbness and dizziness (three participants).

\section{Adverse effects}

In the gabapentin group, 129/241 (53.5\%) participants reported adverse effects and, in the pregabalin group, 142/241 (58.9\%) participants reported adverse effects. Both groups had six $(2.5 \%)$ participants with serious adverse effects. The five most common adverse effects were similar in both groups (somnolence, dizziness, headache, increased weight and dry month).

\section{DISCUSSION}

\section{Summary of main results}

The results of the overall efficacy analysis showed that gabapentin reduced seizure frequency when used as an add-on AED in people with drug-resistant focal epilepsy. Compared to placebo, gabapentin was almost twice as likely to reduce seizures by $50 \%$ or more, however there was considerable discrepancy between the results of the ITT and best-case and worst-case analyses, hence the ITT analyses need to be interpreted with some caution (see Implications for research). The dose-response regression analysis indicated increasing efficacy with increasing dose. Results suggested that the therapeutic effect of gabapentin $600 \mathrm{mg} /$ day, although statistically significant, was small and $900 \mathrm{mg} /$ day would seem a better initial dose. In addition, there was no apparent 'plateau' of therapeutic effects at the doses tested and it may well be that optimal doses of gabapentin have not been tested.

This was also reflected to a much greater extent by the studies described in narrative form. The Tomovic 1999 study comparing gabapentin doses reported $72.2 \%$ of the 18 participants evaluated as having a $50 \%$ or greater reduction in seizure frequency outcome (compared to $16 \%$ to $22 \%$ taken from the studies comparing gabapentin to placebo combined in meta-analysis) even though the demographics and treatment doses were comparable. Similarly, the active control trials reported a $54 \%$ response rate in Lindberger 2000 (compared to vigabatrin), 58\% response rate in French 2016 (compared to pregabalin) and 77\% response rate in Sethi 2002 (compared to lamotrigine). This could potentially be due to two key differences in methodology: the definition of 'drugresistant' focal epilepsy and to the dosing regimens. Lindberger 2000 defined drug resistance as failure to respond to no more than two AED monotherapy regimens and gabapentin was always added to monotherapy. Sethi 2002 only recruited people refractory to carbamazepine monotherapy and $88 \%$ of participants in the Tomovic 1999 study were taking one other AED only. As the remaining studies used people with refractory focal seizures who were established on one or two AEDs and stable doses (apart from Appleton 1999 who allowed three AEDs), the populations are likely to have a less refractory epilepsy. In addition, Lindberger 2000 and Sethi 2002 used a flexible dosing regimen, allowing doses of gabapentin to be increased as tolerated. This high flexibility made dose adjustments possible in response to a lack of seizure control, with doses of gabapentin $3600 \mathrm{mg} /$ day allowed. This may be reflective of the increased efficacy of gabapentin at higher doses yet this flexible dosing method did result in complexity when interpreting the results as the final doses achieved to maintain seizure control have not been specified. At the other end of the spectrum in the Leach 1997 study, despite allowing doses of 2400 $\mathrm{mg}$, only two out of $23(8.7 \%)$ participants achieved $50 \%$ or greater focal seizure control; this may be reflective of the small sample size and the cross-over design. All participants received all doses (1200 mg, $1800 \mathrm{mg}$ and $2400 \mathrm{mg}$ ) with a washout period of four weeks between doses; this dosing pattern may have influenced the efficacy of gabapentin, which may have resulted in period and carry-over effects.

Results for the outcome 'Treatment withdrawal' suggested that gabapentin was well tolerated, as there was no significant difference between gabapentin and placebo. However, the efficacy results suggested that optimal doses of gabapentin may not have been tested and it may well be that higher doses of gabapentin were less well tolerated. With respect to adverse effects, dizziness, fatigue and somnolence were significantly more likely to occur in the gabapentin-treated group. There were insufficient data available for this review to delineate the precise adverse effect profile of this drug.

\section{Overall completeness and applicability of evidence}

The studies reviewed were all of short duration and no conclusions could be drawn regarding the long-term efficacy of gabapentin. One trial recruited children only (Appleton 1999), and the estimate for seizure reduction was low in that study. Caution is required when extrapolating the results of this trial to adults.

In terms of seizure subtypes, Sethi 2002 reported gabapentin's more pronounced effects on simple focal seizures and secondary generalised as opposed to complex focal seizures. This is contrary to the US Gabapentin 1993 study, which observed gabapentin to be more efficacious in complex focal seizures. This review focused on the use of gabapentin in drug-resistant focal epilepsy and the results could not be generalised to add-on treatment in people with generalised epilepsy. Likewise, no inference can be made about the efficacy and tolerability of gabapentin when used as monotherapy.

The results of this review indicated that gabapentin was an effective add-on treatment. We found three head-to-head trials with no study finding a significant difference between gabapentin and the alternative AED (pregabalin, vigabatrin and lamotrigine respectively) (French 2016, Lindberger 2000; Sethi 2002). As clinicians are faced with an ever increasing number of AEDs to choose from, more head-to-head trials are required to provide the evidence that is needed to enable clinicians to make an evidencebased choice between AEDs.

It still remains difficult to predict the differences between a rapid and slow initiation of gabapentin, as the Fisher 2001 study only observed the effects of rapid initiation on the first day of starting the maximum dose and four days later. However, they did contact participants for the subsequent two weeks to report any serious outcomes. These have not been documented in the report, therefore it is difficult to extrapolate data beyond this period. 


\section{Quality of the evidence}

Six out of the 12 studies used adequate methods of concealment of randomisation. All trials were double-blind; however, often little information was reported as to how personnel/outcome assessors were blinded. For the studies included in the meta-analysis, apart from Yamauchi 2006, published reports referred to their analyses as being ITT, with 222 of the 1688 participants recruited excluded from analyses. Reported analyses would perhaps be better called 'exploratory,' as participants who had treatment withdrawn during the treatment period and did not meet the original trial inclusion criteria were excluded from the reported analyses, despite completing the treatment period with adequate seizure data.

Additional data, supplied by Parke Davis, revealed that 38 participants did not complete the treatment phase and nine had inadequate seizure data recorded, hence the percentage reduction in seizure frequency could not be calculated for 47 of these participants. The Yamauchi 2006 study stated that 19 participants were not included in the study and provided reasons for this. The French 2016 study stated that 123 participants withdrew for any reason. Similarly, there was a high risk of attrition bias in the remaining studies, which we discussed in narrative form (Fisher 2001; Leach 1997; Tomovic 1999), apart from the Lindberger 2000 study for which analysis was completely ITT. The Sethi 2002 study did not give any information related to dropouts and, therefore, the risk was uncertain. Selective outcome reporting bias was unclear in Leach 1997, Lindberger 2000, Sethi 2002, and Tomovic 1999 as they mentioned 'seizure activity recorded' without details of the methodology.

Overall the quality of evidence was low to moderate due to potential attrition bias resulting from missing outcome data and imprecise results with wide confidence intervals. Research is needed into the effects of the long-term use of gabapentin.

\section{Potential biases in the review process}

There were discrepancies between study designs that may be reflected in the variability of the results.

Parke Davis sponsored most of trials included in this review, apart from Sethi 2002 and Tomovic 1999. Pfizer Inc., the manufacturer of gabapentin and pregabalin, funded one trial (French 2016).

\section{Agreements and disagreements with other studies or reviews}

We found no reviews or published information on the use of gabapentin as add-on therapy for refractory focal epilepsy.

\section{AUTHORS' CONCLUSIONS}

\section{Implications for practice}

In people with drug-resistant focal epilepsy, gabapentin has efficacy as an add-on treatment. Moderate-quality evidence from this review suggests that a dose of $1800 \mathrm{mg} /$ day will reduce seizure frequency by at least $50 \%$ in $25.3 \%$ of people $(95 \%$ confidence interval $19.3 \%$ to $32.3 \%$ ). Although our results suggest that 600 $\mathrm{mg}$ has a statistically significant effect on seizure frequency, that effect is small and $900 \mathrm{mg} /$ day would seem a more reasonable initial dose. Regression analyses show no plateau of therapeutic effect and it is likely that optimal doses need to be tested in a more standardised manner and final doses provided so that such results can be included in meta-analyses in the future. Doses of up to $2400 \mathrm{mg} /$ day are currently recommended in the British National Formulary.

Low- to moderate-quality evidence suggests that dizziness, fatigue and somnolence occurs significantly more often with gabapentin than placebo; although gabapentin is generally well tolerated.

\section{Implications for research}

\section{The conduct of future 'add-on' trials}

The striking differences between the intention-to-treat, worst-case and best-case analyses for $50 \%$ responder rates has important implications for the conduct of further 'add-on' studies. For the intention-to-treat analysis in this review, all participants lost to follow-up or excluded from analyses due to inadequate seizure recording were assumed to be 'non-responders.' The best-case and worst-case analyses, although representing the extreme, test the effect of making that assumption. When large discrepancies are found, as in this case, the accuracy of individual trials and hence this review is challenged.

The main problem here is that participants having trial treatment withdrawn are no longer followed up. This provides a data set that allows an explanatory 'on treatment analysis,' but precludes a robust intention-to-treat analysis. To minimise this problem, every attempt must be made to follow participants up, even if trial treatment has been withdrawn. This provides the maximum data set from which analyses other than intention-to-treat may be undertaken.

\section{Further evaluation of gabapentin as an antiepileptic drug}

To further evaluate the place of gabapentin in the armamentarium of available antiepileptic drugs, further studies are required which address the following:

1. the efficacy and tolerability of add-on doses higher than 1800 $\mathrm{mg} /$ day in people with drug-resistant focal epilepsy, in clearly specified doses and a clarification as to maximum doses achieved when flexible regimens are employed;

2. the long-term efficacy and tolerability of add-on gabapentin beyond three months;

3. how gabapentin compares with other add-on treatments in drug-resistant focal epilepsy;

4. the role of gabapentin in childhood epilepsies and

5. how gabapentin compares with other standard antiepileptic drugs, such as sodium valproate, as monotherapy in generalised epilepsy.

\section{ACK N O WLEDGEMENTS}

We would like to acknowledge Zakaria Kadir and David W Chadwick for contributing to the original review, as well as Miloš Stojadinović for providing the translation of the Serbian paper.

We would like to acknowledge Alexandra Cunliffe who helped to assess the trials for inclusion in this update.

This review update was supported by the National Institute for Health Research (NIHR), via Cochrane Programme Grant funding 
to the Epilepsy Group. The views and opinions expressed therein are those of the authors and do not necessarily reflect those of the
Systematic Reviews Programme, NIHR, National health Service or the Department of Health. 


\section{R E F E R E N C E S}

\section{References to studies included in this review}

Anhut 1994 \{published and unpublished data\}

Anhut H, Ashman P, Feuerstein TJ, Sauermann W, Saunders M, Schmidt B. Gabapentin (Neurontin) as add-on therapy in patients with partial seizures: a double-blind, placebocontrolled study. Epilepsia 1994;35(4):795-801.

\section{Appleton 1999 \{published data only\}}

Appleton R, Fichtner K, LaMoreaux L, Alexander J, Halsall G, Murray G, et al. and the Gabapentin Paediatric Study Group. Gabapentin as add-on therapy in children with refractory partial seizures: a 12 week, multicentre, double blind placebo controlled study. Epilepsia 1999;40(8):1147-54.

Fisher 2001 \{published data only\}

Fisher RS, Sachdeo RC, Pellock J, Penovich PE, Mahnus L, Bernstein P. Rapid Initiation of gabapentin: a randomised control trial. Neurology 2001;56:743-8.

\section{French 2016 \{published data only\}}

French J, Glue P, Friedman D, Almas M, Yardi N, Knapp L, et al. Adjunctive pregabalin vs gabapentin for focal seizures: Interpretation of comparative outcomes. Neurology 2016;87(12):1242-9.

\section{Leach 1997 \{published data only\}}

Leach JP, Girvan J, Paul A, Brodie MJ. Gabapentin and cognition: a double blind, dose ranging, placebo controlled study in refractory epilepsy. Journal of Neurology, Neurosurgery, and Psychiatry 1997;62(4):372-6.

\section{Lindberger 2000 \{published data only\}}

Lindberger M, Alenius M, Frisen L, Johannessen SI, Larsson S, Malmgren $\mathrm{K}$, et al. on behalf of the GREAT Study Investigators Group. Gabapentin versus vigabatrin as first add-on for patients with partial seizures that failed to respond to monotherapy: a randomised, double-blind, dose titration study. Epilepsia 2000;41(10):1289-95.

\section{Sethi 2002 \{published data only\}}

Sethi A, Chandra D, Puir V, Mallika V. Gabapentin and lamotrigine in Indian patients of partial epilepsy refractory to carbamazepine. Neurology India 2002;50(3):359-63.

\section{Sivenius 1991 \{published and unpublished data\}}

Sivenius J, Kalviainen R, Ylinen A, Riekkinen P. Double blind study of gabapentin in the treatment of partial seizures. Epilepsia 1991;32(4):539-42.

\section{Tomovic 1999 \{published data only\}}

Tomovic M, Ilic T, Mihajlovic M, Jovicic A. Gabapentin as adjuvant therapy in the treatment of refractory partial epilepsy. Vojnosanit Pregl 1999;56(2):151-6.

UK Gabapentin 1990 \{published and unpublished data\} UK Gabapentin Study Group. Gabapentin in partial epilepsy. Lancet 1990;335(8698):1114-7.
US Gabapentin 1993 \{published and unpublished data\}

US Gabapentin Study Group No 5. Gabapentin as add-on therapy in refractory partial epilepsy: a double-blind, placebocontrolled, parallel-group study. Neurology 1993;43(11):2292-8.

\section{Yamauchi 2006 \{published data only\}}

Yamauchi T, Kaneko S, Vagi K, Sase S. Treatment of partial seizures with gabapentin: double-blind, placebo-controlled, parallel-group study. Psychiatry and Clinical Neurosciences 2006;60(4):507-15.

\section{References to studies excluded from this review}

Arya 2013 \{published data only\}

Arya A, Glauser TA. Pharmacotherapy of focal epilepsy in children: a systematic review of approved agents. CNS Drugs 2013;27(4):273-86

\section{Bodalia 2013 \{published data only\}}

Bodalia PN, Grosso AM, Sofat R, Macallister RJ, Smeeth L, Dhillon S. Comparative efficacy and tolerability of antiepileptic drugs for refractory focal epilepsy: systematic review and network meta-analysis reveals the need for long term comparator trials. British Journal of Clinical Pharmacology 2013;76(5):649-67.

\section{Crawford 1987 \{published data only\}}

Crawford P, Ghadiali E, Lane R, Blumhardt L, Chadwick DW. Gabapentin as an antiepileptic drug in man. Journal of Neurology, Neurosurgery, and Psychiatry 1987;50(6):682-6.

Jacoby 2015 \{published data only\}

Jacoby A, Sudell M, Tudur Smith C, Crossley J, Marson AG, Baker GA. Quality-of-life outcomes of initiating treatment with standard and newer antiepileptic drugs in adults with new-onset epilepsy: findings from the SANAD trial. Epilepsia 2015;56(3):460-72.

Korean Gabapentin Study Group 2000 \{published data only\} Korean Gabapentin Study Group. Comparative clinical trial of gabapentin and sodium valproate as add-on therapy in refractory partial epilepsies: open randomized multicenter trial. Journal of Korean Epilepsy Society 2000;4(1):19-26.

\section{Nonoda 2014 \{published data only\}}

Nonoda Y, Iwasaki T, Ishii M. The efficacy of gabapentin in children of partial seizures and the blood levels. Brain \& Development 2014;36(3):194-202.

Ohtsuka 2014 \{published data only\}

Ohtsuka Y. New antiepileptic drugs: characteristics and clinical applications. Japanese Journal of Clinical Medicine 2014;72(5):931-8

\section{Semah 2014 \{published data only\}}

Semah F, Thomas P, Coulbaut S, Derambure P. Early add-on treatment vs alternative monotherapy in patients with partial epilepsy. Epileptic Disorders 2014;16(2):165-74. 


\section{References to studies awaiting assessment}

Kwan $\mathbf{2 0 0 0}$ \{published data only\}

Kwan SY, Yiu CH, Su MS. A double blind study of gabapentin in partial seizures. Epilepsia 2000;41(Suppl):69.

\section{Shapiro 2000 \{published data only\}}

Shapiro DY, Nordli D, Glauser TA, Knapp LE, Greiner M, Purcell TJ, et al. Gabapentin as add-on therapy for refractory partial seizures in children 1-36 months of age: a novel, shortterm, placebo-controlled trial. Epilepsia 2000;41(Suppl 7):106.

\section{Additional references}

\section{Barker-Haliski 2014}

Barker-Haliski M, Sills GJ, White HS. What are the arguments for and against rational therapy for epilepsy?. Advances in Experimental Medicine \& Biology 2014;813:295-308.

\section{British National Formulary}

British National Formulary. www.bnf.org/.

\section{Cockerell 1995}

Cockerell OC, Johnson AL, Sander JW, Hart YM, Shorvon SD. Remission of epilepsy: results from the national general practice study of epilepsy. Lancet 1995;346:140-4.

\section{GRADEpro GDT 2015 [Computer program]}

GRADE Working Group, McMaster University. GRADEpro GDT. Hamilton (ON): GRADE Working Group, McMaster University, 2015.

\section{Hauser 1993}

Hauser WA, Annegers JF, Kurland LT. Incidence of epilepsy and unprovoked seizures in Rochester, Minnesota: 1935-1984. Epilepsia 1993;34:453-68.

\section{Higgins 2011}

Higgins JP, Green S, editor(s). Cochrane Handbook for Systematic Reviews of Interventions Version 5.1.0 (updated March 2011). The Cochrane Collaboration, 2011. Available from handbook.cochrane.org.

\section{Kirkham 2010}

Kirkham J, Dwan K, Altman D, Gamble C, Dodd S, Smyth R, et al. The impact of outcome reporting bias in randomised controlled trials on a cohort of systematic reviews. BMJ 2010;340:c365.

\section{Lefebvre 2011}

Lefebvre C, Manheimer E, Glanville J. Chapter 6: Searching for studies. In: Higgins JPT, Green S, editor(s). Cochrane Handbook for Systematic Reviews of Interventions Version 5.1.0 (updated March 2011). The Cochrane Collaboration, 2011. Available from handbook.cochrane.org/.

\section{CHARACTERISTICS OF STUDIES}

Characteristics of included studies [ordered by study ID]

\section{Loscher 2002}

Loscher W. Current status and future directions in the pharmacotherapy of epilepsy. Trends in Pharmacological Sciences 2002;23(3):113-8.

\section{McClean 1995}

McClean MJ. Gabapentin. Epilepsia 1995;36 Suppl(2):72-86.

\section{McCullagh 1989}

McCullagh P, Nelder JA. Generalized Linear Models. 2nd Edition. London: Chapman and Hall, 1989.

\section{Panebianco 2015}

Panebianco M, Rigby A, Weston J, Marson AG. Vagus nerve stimulation for partial seizures. Cochrane Database of Systematic Reviews 2015, Issue 4. [DOI: 10.1002/14651858.CD002896.pub2]

\section{Reynolds 1981}

Reynolds EH, Shorvon SD, Galbraith AW. Phenytoin for epilepsy: a long term prospective study, assisted by serum level monitoring in previously untreated patients. Epilepsia 1981;22:475.

\section{Scheffer 2017}

Scheffer IE, Berkovic S, Capovilla G, Connolly MB, French J, et al. ILAE classification of the epilepsies: Position paper of the ILAE Commission for Classification and Terminology. Epilepsia 2017;58(4):512-21.

\section{Schünemann 2013}

Schünemann H, Brożek J, Guyatt G, Oxman A, editor(s), Grade Working Group. GRADE handbook for grading quality of evidence and strength of recommendations. Available from www.guidelinedevelopment.org/handbook 2013.

\section{West 2015}

West S, Nolan SJ, Cotton J, Gandhi S, Weston J, Sudan A, et al. Surgery for epilepsy. Cochrane Database of Systematic Reviews 2015, Issue 7. [DOI: 10.1002/14651858.CD010541.pub2]

\section{References to other published versions of this review \\ Al-Bachari 2013}

Al-Bachari S, Pulman J, Hutton JL, Marson AG. Gabapentin add-on for drug-resistant partial epilepsy. Cochrane Database of Systematic Reviews 2013, Issue 7. [DOI: 10.1002/14651858.CD001415.pub2]

\section{Marson 1999}

Marson AG, Kadir ZZ, Hutton JL, Chadwick DW. Gabapentin add-on for drug-resistant partial epilepsy. Cochrane Database of Systematic Reviews 1999, Issue 1. [DOI: 10.1002/14651858.CD001415] 
Anhut 1994

\begin{tabular}{|c|c|}
\hline Methods & $\begin{array}{l}\text { Randomised, double-blind, placebo-controlled, parallel-group study (conducted at } 24 \text { centres in Eu- } \\
\text { rope, Canada, South Africa and Australia) } \\
3 \text { treatment arms: } 1 \text { placebo and } 2 \text { gabapentin } \\
\text { Prospective pre-randomisation baseline period: } 12 \text { weeks } \\
\text { Treatment period: } 12 \text { weeks }\end{array}$ \\
\hline Participants & $\begin{array}{l}\text { All adults } \\
\text { Cross-continent study } \\
\text { Total randomised: } 272 \text {; all with drug-resistant focal epilepsy } \\
109 \text { to placebo; } 111 \text { to gabapentin } 900 \mathrm{mg} ; 52 \text { to gabapentin } 1200 \mathrm{mg} \\
56 \% \text { men } \\
\text { Age range: } 12-67 \text { years } \\
\text { Other AEDs: } \leq 2 \\
\text { Median baseline seizure frequency/28 days: } 10.2 \text { (range } 0.5 \text { to } 634.3 \text { ) }\end{array}$ \\
\hline Interventions & $\begin{array}{l}\text { Gabapentin } 900 \mathrm{mg} / \text { day } \\
\text { Gabapentin } 1200 \mathrm{mg} / \text { day } \\
\text { Placebo } \\
\text { All tablets and packaging were identical in appearance }\end{array}$ \\
\hline Outcomes & $\begin{array}{l}\text { Proportion with a } 50 \% \text { reduction in seizure frequency } \\
\text { Response ratio (= }(T-B) /(T+B) \text { where } T=\text { number of seizures during the treatment period and } B=\text { num- } \\
\text { ber of seizure in the baseline period) } \\
\text { Adverse effects }\end{array}$ \\
\hline Notes & $\begin{array}{l}27 \text { participants excluded from published analyses: } 10 \text { from the placebo group; } 15 \text { from the gabapentin } \\
900 \mathrm{mg} \text { group; } 2 \text { from the gabapentin } 1200 \mathrm{mg} \text { group } \\
\text { Additional unpublished data allowed the inclusion of participants excluded despite completing the } \\
\text { treatment phase with adequate seizure data. The following participants contributed to the best-case } \\
\text { and worst-case sensitivity analyses in this review. } \\
\text { Placebo: 7; gabapentin } 900 \mathrm{mg} \text { : 9; gabapentin } 1200 \mathrm{mg}: 2\end{array}$ \\
\hline
\end{tabular}

Risk of bias

Bias

Authors' judgement Support for judgement

Random sequence genera- Low risk Random permuted blocks to generate sequence for randomisation tion (selection bias)

\begin{tabular}{lll}
\hline $\begin{array}{l}\text { Allocation concealment } \\
\text { (selection bias) }\end{array}$ & Low risk & Allocated sequentially, sealed, numbered packages \\
\hline $\begin{array}{l}\text { Blinding (performance } \\
\text { bias and detection bias) } \\
\text { All outcomes }\end{array}$ & Low risk & Tablets and packaging identical in appearance \\
\hline
\end{tabular}


Anhut 1994 (Continued)

\begin{tabular}{lll}
$\begin{array}{l}\text { Incomplete outcome data } \\
\text { (attrition bias) } \\
\text { All outcomes }\end{array}$ & High risk & $\begin{array}{l}\text { 'As treated' analysis. Disproportionate numbers excluded across groups: } 13 \\
\text { in placebo: } 17 \text { in gabapentin } 900 \text { mg: } 2 \text { in gabapentin } 1200 \text { mg, some exclud- } \\
\text { ed despite completing treatment phase. Exclusions not included in published } \\
\text { analyses }\end{array}$ \\
\hline $\begin{array}{l}\text { Selective reporting (re- } \\
\text { porting bias) }\end{array}$ & Low risk & $\begin{array}{l}\text { Seizure diary for all groups, same outcomes. Published reports include all pre- } \\
\text { specified expected outcomes }\end{array}$ \\
\hline Other bias & High risk & $\begin{array}{l}\text { Trial sponsored by Parke Davis } \\
\text { Study appeared free of other sources of bias }\end{array}$
\end{tabular}

Appleton 1999

\begin{tabular}{|c|c|}
\hline \multirow[t]{3}{*}{ Methods } & $\begin{array}{l}\text { Randomised, double-blind, placebo-controlled, parallel-group study (conducted at } 54 \text { centres in Eu- } \\
\text { rope, South Africa, and the US) }\end{array}$ \\
\hline & Prospective pre-randomisation baseline period: 6 weeks \\
\hline & Treatment period: 12 weeks \\
\hline
\end{tabular}

\begin{tabular}{ll}
\hline Participants & All children \\
& $\begin{array}{l}\text { Cross-continent study. Total randomised 247; all with drug-resistant focal seizures (15\% to } 16 \% \text { had } \\
\text { generalised seizures also) }\end{array}$
\end{tabular}

128 to placebo; 119 to gabapentin

$54 \%$ male

Age range: 3-12 years

Other AEDs: $\leq 3$

Baseline seizure frequency per 28 days: median 26.7 (range 1.3 to 2893)

\begin{tabular}{ll}
\hline Interventions & Gabapentin $600-1800 \mathrm{mg} /$ day (equivalent to $23.2-35.3 \mathrm{mg} / \mathrm{kg} /$ day) \\
& Placebo \\
\hline
\end{tabular}

\begin{tabular}{ll}
\hline Outcomes & Proportion with a $50 \%$ reduction in seizure frequency \\
Response ratio & \\
Adverse effects
\end{tabular}

\section{Notes}

\section{Risk of bias}

\begin{tabular}{lll}
\hline Bias & Authors' judgement & Support for judgement \\
\hline $\begin{array}{l}\text { Random sequence genera- } \\
\text { tion (selection bias) }\end{array}$ & Unclear risk & Method of randomisation not specified \\
\hline $\begin{array}{l}\text { Allocation concealment } \\
\text { (selection bias) }\end{array}$ & Unclear risk & No details provided \\
\hline
\end{tabular}


Appleton 1999 (Continued)

Blinding (performance Unclear risk Study mentions double-blinding; no details bias and detection bias) All outcomes

Incomplete outcome data Low risk $\quad$ All evaluated on an ITT basis
(attrition bias)

All outcomes

$\begin{array}{ll}\begin{array}{l}\text { Selective reporting (re- } \\ \text { porting bias) }\end{array} & \text { Low risk } \\ & \begin{array}{l}\text { The parent/guardian and physician global assessment of participant seizure } \\ \text { frequency and well-being }\end{array}\end{array}$

Other bias High risk Trial sponsored by Parke Davis

Study appeared free of other sources of bias

\section{Fisher 2001}

\begin{tabular}{ll}
\hline Methods & Randomised, double-blind, placebo-controlled, parallel-group study in the US \\
No formal baseline period & Treatment period: 7 days \\
\hline
\end{tabular}

Aged $\geq 12$ years (range 12-82 years)
Multicentre study in the US
720 participants randomised. Initially 320 per dose initiation regimen. Finally, 280 slow initiation regi-
men and 294 rapid initiation, after withdrawals and exclusions for not fulfilling pre-protocol criteria.
All participants with a recent history of focal seizures, with or without secondary generalisation with ei-
ther inadequate seizure control on 1 or 2 anticonvulsants or had been judged to be unable to tolerate
therapeutic dosages of these drugs (reaching maximum tolerated dose of $\geq 1$ anticonvulsant).

280 slow initiation regimen, 294 rapid initiation regimen

Slow initiation; $44.6 \%$ male, rapid initiation: $44.2 \%$ male

Slow initiation: $300 \mathrm{mg}$ day $1,600 \mathrm{mg}$ day 2 , then $900 \mathrm{mg} / \mathrm{day}$
Rapid initiation: 2 -day placebo lead-in followed by $900 \mathrm{mg} /$ day
Total evaluated treatment period: 7 days

\begin{tabular}{ll}
\hline Outcomes & Reports of fatigue, dizziness, somnolence and ataxia \\
\hline Notes & $\begin{array}{l}\text { Study did not have a baseline period and only measured adverse outcomes over a 7-day period (day } 3 \\
\text { (equivalent to 3rd day of active study medication for slow initiation group and first day for rapid initia- } \\
\text { tion group) and day 7)), therefore unable to include in meta-analysis. }\end{array}$
\end{tabular}

\section{Risk of bias}

\begin{tabular}{lll}
\hline Bias & Authors' judgement & Support for judgement \\
\hline $\begin{array}{l}\text { Random sequence genera- } \\
\text { tion (selection bias) }\end{array}$ & Low risk & $\begin{array}{l}\text { Randomisation schedule that assigned each participant number to either the } \\
\text { slow group or the rapid group in a one-to-one manner }\end{array}$ \\
\hline
\end{tabular}


Fisher 2001 (Continued)

Allocation concealment $\quad$ Low risk $\quad$ Number-specific blister packs
(selection bias)

$\begin{array}{ll}\text { Blinding (performance } & \text { Low risk } \\ \text { bias and detection bias) } & \text { Matching placebo, all participants had a 2-day lead-in phase that was un- } \\ \text { known to investigator and participant }\end{array}$

All outcomes

$\begin{array}{lll}\begin{array}{l}\text { Incomplete outcome data } \\ \text { (attrition bias) }\end{array} & \text { High risk } & \begin{array}{l}\text { Per-protocol analysis stated to include participants who met the criteria for } \\ \text { evaluation (not ITT analysis). } 781 \text { enrolled, only } 574 \text { analysed for } 3 \text { reasons: in- } \\ \text { All outcomes }\end{array} \\ \end{array}$

Selective reporting (re- Low risk Appeared all expected and prespecified outcomes were reported
porting bias)

$\begin{array}{ll}\text { Other bias } & \text { High risk } \\ & \text { Strial sponsored by Parke Davis } \\ & \end{array}$

\title{
French 2016
}

Randomised, flexible dose, double-blind, parallel-group study
2 active treatment arms: 1 gabapentin and 1 pregabalin
Multicentre study: 56 centres (Eastern and Western Europe, Asia South and Central America)
3 main phases: 6 weeks of baseline (screening), 9 weeks of double-blind dose escalation (titration) and
12 weeks of double-blind maintenance phase (21-week treatment phase)

Participants
Inclusion criteria: aged $18-80$ years; diagnosis of epilepsy with focal-onset seizures, inadequately con-
trolled with $\leq 2$ to $\geq 5$ prior AEDs, receiving 1 or 2 standard AEDs (other than gabapentin or pregabalin),
with a minimum of 4 focal-onset seizures during the 6 -week baseline phase with no 28 -day focal-on-
set-seizure-free period.

561 participants screened and 484 randomised: 242 to gabapentin and 242 to pregabalin

Number of people who received intended treatment: 241 gabapentin and 241 pregabalin

Number of people who completed the maintenance phase of the study: 172 gabapentin (69 discontinued treatment) and 187 pregabalin (54 discontinued treatment).

Age (mean): gabapentin 35.3 (SD 12.9) years; pregabalin 34.9 (SD 13.0) years

Age at epilepsy diagnosis (mean): gabapentin 19.9 years; pregabalin 19.8 years

Time since diagnosis of epilepsy: gabapentin 15.8 years; pregabalin 15.6 years

Sex of participants: gabapentin 130 men and 111 women; pregabalin 127 men and 114 women

Interventions

\begin{abstract}
Intervention (241 participants): gabapentin $(300 \mathrm{mg} /$ day, $600 \mathrm{mg} /$ day, $1200 \mathrm{mg} / \mathrm{day}, 1500 \mathrm{mg} /$ day, 1800 mg/day);

Active control (241 participants): pregabalin (150 mg/day, 300 mg/day, 450 mg/day, $600 \mathrm{mg} /$ day).

During the 9-week dose-escalation phase the minimum maintenance phase dose was gabapentin 1200 $\mathrm{mg} /$ day and pregabalin $300 \mathrm{mg} /$ day TDS. During the 21 -week double-blind phase of the study, the median doses were gabapentin $1500 \mathrm{mg} /$ day and pregabalin $450 \mathrm{mg} /$ day.
\end{abstract}


French 2016 (Continued)

Outcomes
Seizure frequency: $\geq 50 \%$ reduction of seizures; $\geq 75 \%$ reduction of seizures

Seizure freedom (for final 28 days)

Withdrawals: any reasons and due to adverse effects

Adverse effects (more common): somnolence, dizziness, headache, increased weight and dry mouth

Notes Clinical Trials.gov ID NCT00537940

\title{
Risk of bias
}

\begin{tabular}{|c|c|c|}
\hline Bias & Authors' judgement & Support for judgement \\
\hline $\begin{array}{l}\text { Random sequence genera- } \\
\text { tion (selection bias) }\end{array}$ & Low risk & Computer-generated randomisation method used \\
\hline $\begin{array}{l}\text { Allocation concealment } \\
\text { (selection bias) }\end{array}$ & Low risk & Randomised participants to either gabapentin or pregabalin (1:1) \\
\hline $\begin{array}{l}\text { Blinding (performance } \\
\text { bias and detection bias) } \\
\text { All outcomes }\end{array}$ & Unclear risk & $\begin{array}{l}\text { No details provided regarding blinding of study personnel, participants and } \\
\text { outcome assessors }\end{array}$ \\
\hline $\begin{array}{l}\text { Incomplete outcome data } \\
\text { (attrition bias) } \\
\text { All outcomes }\end{array}$ & Low risk & $\begin{array}{l}242 \text { participants allocated to gabapentin; } 241 \text { received treatment; } 172 \text { com- } \\
\text { pleted maintenance phase; } 69 \text { participants withdrew } \\
242 \text { participants allocated to pregabalin allocation; } 241 \text { received treatment; } \\
187 \text { completed maintenance phase; } 54 \text { participants withdrew } \\
\text { The reasons for exclusion were reported. }\end{array}$ \\
\hline $\begin{array}{l}\text { Selective reporting (re- } \\
\text { porting bias) }\end{array}$ & Low risk & $\begin{array}{l}\text { Protocol unavailable to check a priori outcomes, but appeared all expected } \\
\text { and prespecified outcomes were reported }\end{array}$ \\
\hline Other bias & High risk & $\begin{array}{l}\text { Study funded by Pfizer Inc., the manufacturer of gabapentin and pregabalin } \\
\text { Study appeared free of other sources of bias }\end{array}$ \\
\hline
\end{tabular}

Leach 1997

\begin{tabular}{|c|c|}
\hline \multirow[t]{2}{*}{ Methods } & $\begin{array}{l}\text { Double-blind, random order, cross-over, placebo-controlled study in the UK } \\
12 \text { weeks' treatment or placebo }\end{array}$ \\
\hline & $\begin{array}{l}\text { No baseline period, however all participants reported at least } 4 \text { seizures/month for } 3 \text { months and AED } \\
\text { doses had remained unchanged for } \geq 3 \text { months prior to study }\end{array}$ \\
\hline
\end{tabular}

\section{Participants}

\author{
Single centre (Western Infirmary in Glasgow, UK) \\ Adults with focal seizures refractory to 1 or 2 AEDs \\ Total randomised: 27 participants; 23 analysed after withdrawals \\ Aged 16-67 years, mean 28.4 years \\ $37 \%$ men prior to withdrawals
}


Leach 1997 (Continued)

Placebo

\begin{tabular}{|c|c|c|}
\hline \multirow[t]{4}{*}{ Outcomes } & \multicolumn{2}{|l|}{ Seizure frequency } \\
\hline & \multicolumn{2}{|l|}{ Seizure freedom } \\
\hline & \multicolumn{2}{|c|}{ Adverse effects (scored, individual adverse effects not mentioned) } \\
\hline & \multicolumn{2}{|c|}{$\begin{array}{l}\text { Neuropsychological tests (psychomotor, memory, cognition, dysphoria, temper, fatigue, worry, tired- } \\
\text { ness) }\end{array}$} \\
\hline Notes & \multicolumn{2}{|c|}{ No baseline period, therefore not included in meta-analysis } \\
\hline \multicolumn{3}{|l|}{ Risk of bias } \\
\hline Bias & Authors' judgement & Support for judgement \\
\hline $\begin{array}{l}\text { Random sequence genera- } \\
\text { tion (selection bias) }\end{array}$ & Unclear risk & No details of randomisation provided \\
\hline $\begin{array}{l}\text { Allocation concealment } \\
\text { (selection bias) }\end{array}$ & Unclear risk & No details provided \\
\hline $\begin{array}{l}\text { Blinding (performance } \\
\text { bias and detection bias) } \\
\text { All outcomes }\end{array}$ & Unclear risk & Double-blind and matched placebo but no further details provided. \\
\hline $\begin{array}{l}\text { Incomplete outcome data } \\
\text { (attrition bias) } \\
\text { All outcomes }\end{array}$ & High risk & $25 \%$ of participants excluded and not analysed on an ITT basis \\
\hline $\begin{array}{l}\text { Selective reporting (re- } \\
\text { porting bias) }\end{array}$ & Low risk & Included all prespecified expected outcomes \\
\hline Other bias & High risk & Trial sponsored by Parke Davis \\
\hline & & Study appeared free of other sources of bias \\
\hline
\end{tabular}

Lindberger 2000

Methods Randomised, double-blind, dose titration study comparing gabapentin with vigabatrin (Denmark, Finland, Iceland, Norway and Sweden)

8-week baseline period, 24-week treatment period, evaluation period at 8 weeks compared with baseline.

To allow flexibility, this was a dose adjustment regimen, with increases in doses of drug based on participant tolerance and seizure control, increased if required at 4-week periods, with a maximum treatment period at each dose of 8 weeks.

Multicentre in 34 Nordic countries
$\begin{aligned} & 102 \text { participants randomised, then } 35 \text { (gabapentin group) and } 44 \text { (vigabatrin group) post exclusions for } \\ & \text { not for fulfilling criteria } \\ & \text { People with focal epilepsy who had tried no more than } 2 \text { AED monotherapy regimens }\end{aligned}$


Lindberger 2000 (Continued)

Interventions
Gabapentin: variable dose $1800 \mathrm{mg} /$ day minimum, then $2400 \mathrm{mg}$ then maximum $3600 \mathrm{mg} /$ day, increased every 8 weeks as tolerated

Vigabatrin: initial $1000 \mathrm{mg}$ then $2000 \mathrm{mg}$ then $4000 \mathrm{mg}$ increased in the same manner as gabapentin

\section{adverse effects}

Seizure reduction rate: proportion of participants with $50 \%$ seizure reduction irrespective of adverse effects

Responder rate: proportion of seizure-free participants without adverse effects

Secondary outcomes: quality of life measures, adverse effects, perimetry

Notes Results provided did not indicate the doses the participants had achieved of each drug

\section{Risk of bias}

\begin{tabular}{lll}
\hline Bias & Authors' judgement & Support for judgement \\
\hline $\begin{array}{l}\text { Random sequence genera- } \\
\text { tion (selection bias) }\end{array}$ & Unclear risk & Not specified \\
\hline $\begin{array}{l}\text { Allocation concealment } \\
\text { (selection bias) }\end{array}$ & Unclear risk & No details provided \\
\hline $\begin{array}{l}\text { Blinding (performance } \\
\text { bias and detection bias) } \\
\text { All outcomes }\end{array}$ & Low risk & $\begin{array}{l}\text { Double-dummy technique, participants received active drug and correspond- } \\
\text { ing placebo }\end{array}$ \\
\hline $\begin{array}{l}\text { Incomplete outcome data } \\
\text { (attrition bias) } \\
\text { All outcomes }\end{array}$ & Low risk & Analysed on an ITT basis \\
\hline $\begin{array}{l}\text { Selective reporting (re- } \\
\text { porting bias) }\end{array}$ & Low risk & Seizure activity reported \\
\hline $\begin{array}{l}\text { Other bias } \\
\text { High risk }\end{array}$ & & Trial sponsored by Parke Davis \\
\hline
\end{tabular}

Sethi 2002

\begin{tabular}{|c|c|}
\hline \multirow[t]{4}{*}{ Methods } & Randomised control trial in India \\
\hline & Head-to-head trial; 2 treatment groups gabapentin and lamotrigine \\
\hline & Treatment period: 12 weeks \\
\hline & $\begin{array}{l}\text { No formal baseline period (however, all had } \geq 4 \text { seizures, unclear over what time, despite treatment } \\
\text { with maximum dose carbamazepine monotherapy) }\end{array}$ \\
\hline \multirow[t]{3}{*}{ Participants } & 52 children and adults \\
\hline & Indian study \\
\hline & Refractory focal seizures \\
\hline
\end{tabular}


Sethi 2002 (Continued)

\section{$48 \%$ male}

27 gabapentin (19 male: 8 female), 25 lamotrigine ( 6 male: 19 female)

Aged $10-60$ years

Interventions

Gabapentin: $300 \mathrm{mg}$ day 1, $300 \mathrm{mg}$ twice daily day 2, there after an increment of $300 \mathrm{mg}$ daily until $\geq$ $50 \%$ reduction in seizures or toxic effects

Lamotrigine: $50 \mathrm{mg} /$ day for 2 weeks, increased to $50 \mathrm{mg}$ twice daily, subsequently an increase of 50-100 mg daily until above criteria met

Outcomes

Efficacy: seizure frequency, pattern of seizures, seizure-free interval. Including $\%$ change of seizure frequency from baseline, responder rate (reduction in seizure frequency of $\geq 50 \%$ ), response ratio

Safety: biochemical investigations and adverse effects

Notes As no clear baseline period, excluded from meta-analysis

\section{Risk of bias}

\begin{tabular}{|c|c|c|}
\hline Bias & Authors' judgement & Support for judgement \\
\hline $\begin{array}{l}\text { Random sequence genera- } \\
\text { tion (selection bias) }\end{array}$ & Unclear risk & No details provided \\
\hline $\begin{array}{l}\text { Allocation concealment } \\
\text { (selection bias) }\end{array}$ & Unclear risk & No details provided \\
\hline $\begin{array}{l}\text { Blinding (performance } \\
\text { bias and detection bias) } \\
\text { All outcomes }\end{array}$ & Unclear risk & No details provided \\
\hline $\begin{array}{l}\text { Incomplete outcome data } \\
\text { (attrition bias) } \\
\text { All outcomes }\end{array}$ & Unclear risk & $\begin{array}{l}\text { No participants seemed to be excluded from the results, but } 1 \text { participant in } \\
\text { gabapentin group did not seem to be accounted for }\end{array}$ \\
\hline $\begin{array}{l}\text { Selective reporting (re- } \\
\text { porting bias) }\end{array}$ & Low risk & Included all prespecified expected outcomes \\
\hline Other bias & Low risk & Study appeared free of other sources of bias \\
\hline
\end{tabular}

Sivenius 1991

\begin{tabular}{ll} 
Methods & Randomised, double-blind, placebo-controlled, parallel-group study in Finland \\
& 3 treatment arms: 1 placebo and 2 gabapentin \\
& Prospective pre-randomisation baseline period: 12 weeks \\
& Treatment period: 12 weeks \\
\hline Participants & All adults \\
& Total randomised: 45 participants; all with drug-resistant focal epilepsy \\
& 18 placebo; 18 gabapentin $900 \mathrm{mg} /$ day; 9 gabapentin $1200 \mathrm{mg} /$ day \\
$47 \%$ men
\end{tabular}


Sivenius 1991 (Continued)

Aged 16-59 years

Other AEDs: $\leq 2$

Median baseline seizure frequency per 12-week baseline period: 36 placebo; 26 gabapentin $900 \mathrm{mg} /$ day; 23 gabapentin $1200 \mathrm{mg} /$ day

\begin{tabular}{ll}
\hline Interventions & Gabapentin $900 \mathrm{mg} /$ day \\
& Gabapentin $1200 \mathrm{mg} /$ day \\
& Placebo \\
& All treatments and packaging were identical in appearance \\
\hline Outcomes & Median change in seizure frequency \\
& \% change in seizure frequency \\
& Adverse effects \\
\hline Notes & $\begin{array}{l}\text { 2 people in the gabapentin } 900 \text { mg group were excluded from analysis, both excluded } 2 \text { weeks' pos- } \\
\text { trandomisation. }\end{array}$ \\
\hline
\end{tabular}

\section{Risk of bias}

\begin{tabular}{|c|c|c|}
\hline Bias & Authors' judgement & Support for judgement \\
\hline $\begin{array}{l}\text { Random sequence genera- } \\
\text { tion (selection bias) }\end{array}$ & Low risk & Allocated sequentially, sealed, numbered packages \\
\hline $\begin{array}{l}\text { Allocation concealment } \\
\text { (selection bias) }\end{array}$ & Low risk & Random permuted blocks \\
\hline $\begin{array}{l}\text { Blinding (performance } \\
\text { bias and detection bias) } \\
\text { All outcomes }\end{array}$ & Low risk & Tablets and packaging identical in appearance. Identical analysis of results \\
\hline $\begin{array}{l}\text { Incomplete outcome data } \\
\text { (attrition bias) } \\
\text { All outcomes }\end{array}$ & Unclear risk & $\begin{array}{l}\text { No reasons reported for exclusion of } 2 \text { participants in gabapentin } 900 \mathrm{mg} \\
\text { group }\end{array}$ \\
\hline $\begin{array}{l}\text { Selective reporting (re- } \\
\text { porting bias) }\end{array}$ & Low risk & $\begin{array}{l}\text { Quote: "... seizure frequency was recorded" } \\
\text { Unclear how, otherwise included all prespecified expected outcomes }\end{array}$ \\
\hline Other bias & High risk & $\begin{array}{l}\text { Trial sponsored by Parke Davis } \\
\text { Study appeared free of other sources of bias }\end{array}$ \\
\hline
\end{tabular}

Tomovic 1999

\begin{tabular}{ll}
\hline Methods & Randomised, parallel-group study in Serbia \\
\hline Participants & 9 women and 9 men with refractory focal epilepsy. Serbian adults. \\
& Mean age: 24.7 years, range $17-47$ years \\
& Drug-resistant focal epilepsy
\end{tabular}


Tomovic 1999 (Continued)

All had been treated with 1 or 2 first-line AEDs during 3 months before introducing gabapentin with unsatisfactorily controlled seizures

Seizure frequency prior to treatment was unclear

\begin{tabular}{ll}
\hline Interventions & Gabapentin $900 \mathrm{mg}$ \\
& Gabapentin $1200 \mathrm{mg}$ \\
\hline Outcomes & Seizure frequency \\
& Seizure freedom \\
& Haematological and biochemical analyses (4th and 12th week) and 24-hour EEG on before therapy and \\
on final week (week 12). Frequency of epileptiform discharges noted & \\
& Reduction in seizure activity: 26\%-49\%; 50-99\%; 100\%; worse state \\
& Adverse effects \\
\hline Notes & demographics, etc.) \\
\hline
\end{tabular}

\section{Risk of bias}

\begin{tabular}{|c|c|c|}
\hline Bias & Authors' judgement & Support for judgement \\
\hline $\begin{array}{l}\text { Random sequence genera- } \\
\text { tion (selection bias) }\end{array}$ & Unclear risk & Method of randomisation unclear \\
\hline $\begin{array}{l}\text { Allocation concealment } \\
\text { (selection bias) }\end{array}$ & Unclear risk & How participants allocated to each group unclear \\
\hline $\begin{array}{l}\text { Blinding (performance } \\
\text { bias and detection bias) } \\
\text { All outcomes }\end{array}$ & Unclear risk & Unclear if tablets and packaging identical in appearance \\
\hline $\begin{array}{l}\text { Incomplete outcome data } \\
\text { (attrition bias) } \\
\text { All outcomes }\end{array}$ & High risk & Unclear why 3 participants dropped out and excluded from analysis \\
\hline $\begin{array}{l}\text { Selective reporting (re- } \\
\text { porting bias) }\end{array}$ & Low risk & $\begin{array}{l}\text { Seizure frequency recorded; unclear how seizure activity measured. Otherwise } \\
\text { standardised tests for both groups }\end{array}$ \\
\hline Other bias & Low risk & Study appeared free of other sources of bias \\
\hline
\end{tabular}

\section{UK Gabapentin 1990}

\begin{tabular}{ll} 
Methods & Randomised, double-blind, placebo-controlled, parallel-grou \\
& Prospective pre-randomisation baseline period: 12 weeks \\
& Treatment period: 14 weeks \\
\hline Participants & All adults \\
Cross-continent study \\
Total randomised: 127 ; all with drug-resistant focal epilepsy
\end{tabular}


UK Gabapentin 1990 (Continued)

Placebo: 66 participants; gabapentin $1200 \mathrm{mg} /$ day: 61 participants

$39 \%$ men

Age range: $14-73$ years

Other AEDs: $\leq 2$

Median baseline seizure frequency/28 days: gabapentin 13 (range 3 to 368); placebo 13 (range 1 to 216 )

$\begin{array}{ll}\text { Interventions } & \text { Gabapentin } 1200 \mathrm{mg} / \text { day } \\ \text { Placebo } & \text { All treatments and packaging identical in appearance }\end{array}$

$\begin{array}{ll}\text { Outcomes } & \text { Proportion with a 50\% reduction in seizure frequency } \\ & \text { Response ratio } \\ & \text { Adverse effects } \\ & 14 \text { participants excluded from published analyses: } 5 \text { from the placebo group; } 9 \text { from the gabapentin } \\ & 1200 \mathrm{mg} / \text { day group } \\ \text { Notes } & \text { Additional unpublished data allowed the inclusion of participants excluded despite completing the } \\ \text { treatment phase with adequate seizure data. The following participants contribute to the best-case } \\ \text { and worst-case sensitivity analyses in this review. } \\ \text { Placebo: } 2 \text {; gabapentin } 1200 \mathrm{mg}: 8\end{array}$

\section{Risk of bias}

\begin{tabular}{lll}
\hline Bias & Authors' judgement & Support for judgement \\
\hline $\begin{array}{l}\text { Random sequence genera- } \\
\text { tion (selection bias) }\end{array}$ & Low risk & Used random permuted blocks to generate sequence for randomisation \\
\hline $\begin{array}{l}\text { Allocation concealment } \\
\text { (selection bias) }\end{array}$ & Low risk & Allocated sequentially, sealed, numbered packages \\
\hline
\end{tabular}

Blinding (performance $\quad$ Low risk $\quad$ Used tablets and packaging identical in appearance
bias and detection bias)

All outcomes

\begin{tabular}{lll}
\hline $\begin{array}{l}\text { Incomplete outcome data } \\
\text { (attrition bias) }\end{array}$ & High risk & Attrition rate reported, 14 participants who withdrew were not included in \\
published analyses. Report withdrawals and gave reasons for withdrawal.
\end{tabular}

All outcomes

Selective reporting (re- Low risk $\quad$ Included all prespecified, expected outcomes
porting bias)
porting bias)

\begin{tabular}{ll}
\hline Other bias & High risk \\
& Trial sponsored by Parke Davis \\
& Study appeared free of other sources of bias \\
\hline
\end{tabular}

\section{US Gabapentin 1993}

Methods Randomised, double-blind, placebo-controlled, parallel-group study in the US


US Gabapentin 1993 (Continued)

4 treatment arms: 1 placebo and 3 gabapentin

Prospective pre-randomisation baseline period: 12 weeks

Treatment period: 12 weeks

\begin{tabular}{|c|c|}
\hline \multirow[t]{8}{*}{ Participants } & All adults \\
\hline & USA study \\
\hline & Total randomised: 306 participants; all with drug-resistant focal epilepsy \\
\hline & $\begin{array}{l}\text { Placebo: } 98 \text { participants; gabapentin } 600 \text { mg/day: 53; gabapentin } 1200 \text { mg/day: 101; gabapentin } 1800 \\
\text { mg/day: } 54\end{array}$ \\
\hline & $66 \%$ men \\
\hline & Aged $16-70$ years \\
\hline & Other AEDs: $\leq 2$ \\
\hline & Median baseline seizure frequency/28 days: 10.8 (range $2.0-1092.7$ ) \\
\hline \multirow[t]{5}{*}{ Interventions } & Gabapentin 600 mg/day \\
\hline & Gabapentin 1200 mg/day \\
\hline & Gabapentin 1800 mg/day \\
\hline & Placebo \\
\hline & All treatments and packages were identical in appearance \\
\hline \multirow[t]{3}{*}{ Outcomes } & Proportion with a $50 \%$ reduction in seizure frequency \\
\hline & Response ratio \\
\hline & Adverse effects \\
\hline \multirow[t]{2}{*}{ Notes } & $\begin{array}{l}18 \text { participants excluded from published analyses: placebo: 3; gabapentin } 600 \mathrm{mg} / \text { day: 4; gabapentin } \\
1200 \mathrm{mg} \text { /day: } 10 \text {; gabapentin } 1800 \mathrm{mg} / \text { day: } 1\end{array}$ \\
\hline & $\begin{array}{l}\text { Additional unpublished data allowed the inclusion of participants excluded despite completing the } \\
\text { treatment phase with adequate seizure data. The following participants contribute to the best-case } \\
\text { and worst-case sensitivity analyses in this review. Placebo: 2; gabapentin } 600 \mathrm{mg} / \text { day: 4; gabapentin } \\
1200 \mathrm{mg} / \text { day: 10; gabapentin } 1800 \mathrm{mg} / \text { day: } 1\end{array}$ \\
\hline
\end{tabular}

\section{Risk of bias}

\begin{tabular}{lll}
\hline Bias & Authors' judgement & Support for judgement \\
\hline $\begin{array}{l}\text { Random sequence genera- } \\
\text { tion (selection bias) }\end{array}$ & Low risk & Used random permuted blocks to generate sequence for randomisation \\
\hline $\begin{array}{l}\text { Allocation concealment } \\
\text { (selection bias) }\end{array}$ & Low risk & Allocated sequentially, sealed, numbered packages \\
\hline $\begin{array}{l}\text { Blinding (performance } \\
\text { bias and detection bias) } \\
\text { All outcomes }\end{array}$ & Low risk & Used tablets and packaging identical in appearance \\
\hline $\begin{array}{l}\text { Incomplete outcome data } \\
\text { (attrition bias) }\end{array}$ & High risk & $\begin{array}{l}\text { Attrition rate reported, 18 participants not included in published analyses and } \\
\text { no reasons given }\end{array}$ \\
\hline
\end{tabular}


US Gabapentin 1993 (Continued)

All outcomes

Selective reporting (re- Low risk Included all prespecified expected outcomes
porting bias)

$\begin{array}{ll}\text { Other bias } & \text { High risk } \\ & \text { Stud sponsored by Parke Davis } \\ & \end{array}$

Yamauchi 2006

Randomised, double-blind, placebo-controlled, parallel-group study in Japan
Prospective pre-randomisation baseline period: 12 weeks
Treatment period: 12 weeks
Dose-reduction period lasting 8 days, 4 weeks instituted, followed by a 4-week post-dosing observation
period
3 treatment arms, 1 placebo and 2 treatment

\section{Participants}

Adults aged $\geq 16$ years

Most aged 18-44 years, mean age between 3 groups 31-33 years

Multicentre Japanese study from March 2000 to October 2002

Other AEDs: > 1

Total randomised 209 participants; all with drug-resistant focal epilepsy

82 participants to placebo (42 men, mean age: 31.8 (SD 11.3) years, 25 secondary generalised seizures, mean duration epilepsy: 19.5 years, mean seizure frequency/28 days: $19.9,1$ other AED: $19.5 \%$, 2 other AEDs: $80.5 \%$ )

86 participants to gabapentin $1200 \mathrm{mg}$ (37 men, mean age 31.3 (SD 10.6) years, 26.3 secondary generalised seizures, mean duration epilepsy: 19.8 years, mean seizure frequency/28 days: $31.6,1$ other AED: 14\%, 2 other AEDs: $86 \%$ )

41 participants to gabapentin $1800 \mathrm{mg}$ (22 men, mean age 32.7 (SD 13.7) years, 13 secondary generalised seizures, mean duration epilepsy: 21.2 years, mean seizure frequency/28 days: $24.2,1$ other AED: 4.9\%, 2 other AEDs: 95.1\%)

19 excluded; after exclusion placebo: 75, gabapentin 1200 mg: 80, gabapentin 1800 mg: 35

Baseline seizure frequency/12 weeks: 8

Interventions
Gabapentin $1200 \mathrm{mg} /$ day
Gabapentin $1800 \mathrm{mg} /$ day
Placebo
All treatments were identical in appearance (200 mg tablets)

Outcomes

Improvement in seizure frequency: completely (-100\%), markedly improved (-99.9\% to $-75.0 \%)$, moderately improved $(-74.9 \%$ to $-50 \%)$, slightly improved $(-49.9 \%$ to $-25 \%)$, no change $(-24.9 \%$ to $0 \%)$, aggravated $(>+0.1 \%)$ 
Yamauchi 2006 (Continued)

Response ratio $(=(T-B) /(T+B)$ where $T=$ number of seizures during the treatment period, and $B=$ number of seizure in the baseline period)

Seizure intensity/duration: better, no change and worse

Adverse effects

Serious treatment-related adverse effects

Notes

\section{Risk of bias}

\begin{tabular}{lll}
\hline Bias & Authors' judgement & Support for judgement \\
\hline $\begin{array}{l}\text { Random sequence genera- } \\
\text { tion (selection bias) }\end{array}$ & Unclear risk & $\begin{array}{l}\text { Little/no detail regarding randomisation given. Most variables between groups } \\
\text { controlled (age, sex, frequency, number of other AED, previous treatments } \\
\text { etc.) }\end{array}$ \\
\hline $\begin{array}{l}\text { Allocation concealment } \\
\text { (selection bias) }\end{array}$ & Unclear risk & Insufficient information provided \\
\hline $\begin{array}{l}\text { Blinding (performance } \\
\text { bias and detection bias) } \\
\text { All outcomes }\end{array}$ & Low risk & $\begin{array}{l}\text { Tablets identical in appearance, all outcomes blinded, monitored and fol- } \\
\text { lowed up in the same way }\end{array}$ \\
\hline $\begin{array}{l}\text { Incomplete outcome data } \\
\text { (attrition bias) } \\
\text { All outcomes }\end{array}$ & High risk & $\begin{array}{l}\text { ITT analysis not employed; reasons for exclusions stated; however, 19 partici- } \\
\text { pants not included }\end{array}$ \\
\hline $\begin{array}{l}\text { Selective reporting (re- } \\
\text { porting bias) }\end{array}$ & Low risk & $\begin{array}{l}\text { Seizure diary for all groups, same outcomes. Published reports include all pre- } \\
\text { specified expected outcomes }\end{array}$ \\
\hline $\begin{array}{l}\text { Other bias } \\
\text { High risk }\end{array}$ & $\begin{array}{l}\text { Trial sponsored by Parke Davis } \\
\text { Study appeared free of other sources of bias }\end{array}$ \\
\hline
\end{tabular}

AED: antiepileptic drug; EEG: electroencephalogram; ITT: intention-to-treat; SD: standard deviation; TDS: three times daily.

Characteristics of excluded studies [ordered by study ID]

\begin{tabular}{ll}
\hline Study & Reason for exclusion \\
\hline Arya 2013 & Not an RCT \\
\hline Bodalia 2013 & Not an RCT \\
\hline Crawford 1987 & No seizure data recorded \\
\hline Jacoby 2015 & Ineligible population (new-onset epilepsy) \\
\hline Korean Gabapentin Study Group 2000 & No gabapentin in add-on (sodium valproate in add-on) \\
\hline Nonoda 2014 & Ineligible population (no refractory epilepsy) \\
\hline Ohtsuka 2014 & Not an RCT \\
\hline
\end{tabular}




\begin{tabular}{ll}
\hline Study & Reason for exclusion \\
\hline Semah 2014 & No gabapentin in add-on \\
\hline
\end{tabular}

$\mathrm{RCT}$ : randomised controlled trial.

Characteristics of studies awaiting assessment [ordered by study ID]

Kwan 2000

\begin{tabular}{ll}
\hline Methods & Double-blind, randomised, placebo-controlled, cross-over study in China \\
\hline Participants & 43 adults with refractory focal seizures \\
\hline Interventions & Gabapentin $600 \mathrm{mg} /$ day for 1 week and $1200 \mathrm{mg} /$ day for 12 weeks with matching placebo controls \\
\hline Outcomes & $\begin{array}{l}\text { A statistically significant difference in seizure frequency from the baseline to the treatment phase } \\
\text { was noted between patients receiving placebo and GBP } 1,200 \text { mg, in whom seizure frequency de- } \\
\text { creased } 57 \% \text {. The GBP dosage of } 900 \text { mg appeared to be ineffective. A close relationship was ob- } \\
\text { served between the serum GBP concentrations and the GBP dosage based on the seizure frequen- } \\
\text { cy. Serum GBP concentrations greater than } 2 \text { micrograms/ml resulted in a lower frequency of } \\
\text { seizures. }\end{array}$
\end{tabular}

Notes

No other data available for analysis; all data taken from abstract; author unable to provide further information

Shapiro 2000

\begin{tabular}{ll}
\hline Methods & Randomised, placebo-controlled trial in US \\
\hline Participants & 76 young children with focal epilepsy \\
\hline Interventions & Syrup formulation of gabapentin $40 \mathrm{mg} / \mathrm{kg} /$ day given TDS or placebo \\
\hline Outcomes & $\begin{array}{l}\text { Main outcome was seizure reduction. Concluded that gabapentin was safe and well tolerated, and } \\
\text { reduced the rate of focal seizures; however, this finding did not reach significance }\end{array}$
\end{tabular}

Notes

All information taken from abstract, unable to contact study authors

SD: standard deviation; TDS: three times daily.

\section{DATA AND ANALYSES}

Comparison 1. Gabapentin versus placebo

\begin{tabular}{lllll}
\hline Outcome or subgroup title & $\begin{array}{l}\text { No. of } \\
\text { studies }\end{array}$ & $\begin{array}{l}\text { No. of } \\
\text { partici- } \\
\text { pants }\end{array}$ & Statistical method & Effect size \\
\hline $\begin{array}{l}1 \text { Reduction in seizure frequency } \\
\geq 50 \%\end{array}$ & 6 & & Risk Ratio (M-H, Fixed, 95\% Cl) & Subtotals only \\
\hline
\end{tabular}




\begin{tabular}{|c|c|c|c|c|}
\hline Outcome or subgroup title & $\begin{array}{l}\text { No. of } \\
\text { studies }\end{array}$ & $\begin{array}{l}\text { No. of } \\
\text { partici- } \\
\text { pants }\end{array}$ & Statistical method & Effect size \\
\hline 1.1 Primary analysis & 6 & 1206 & Risk Ratio (M-H, Fixed, 95\% Cl) & $1.89[1.40,2.55]$ \\
\hline 1.2 Sensitivity (best-case) & 6 & 1206 & Risk Ratio (M-H, Fixed, 95\% Cl) & $2.52[1.89,3.37]$ \\
\hline 1.3 Sensitivity (worst-case) & 6 & 1206 & Risk Ratio (M-H, Fixed, 95\% Cl) & $1.35[1.04,1.76]$ \\
\hline 2 Treatment withdrawal & 6 & 1206 & Risk Ratio (M-H, Fixed, 95\% Cl) & $1.05[0.74,1.49]$ \\
\hline 3 Adverse effects & 6 & & Risk Ratio (M-H, Fixed, 99\% Cl) & Subtotals only \\
\hline 3.1 Ataxia & 3 & 787 & Risk Ratio (M-H, Fixed, 99\% Cl) & $2.01[0.98,4.11]$ \\
\hline 3.2 Dizziness & 6 & 1206 & Risk Ratio (M-H, Fixed, 99\% Cl) & $2.43[1.44,4.12]$ \\
\hline 3.3 Fatigue & 5 & 1161 & Risk Ratio (M-H, Fixed, 99\% Cl) & $1.95[0.99,3.82]$ \\
\hline 3.4 Headache & 6 & 1206 & Risk Ratio (M-H, Fixed, 99\% Cl) & $0.79[0.46,1.35]$ \\
\hline 3.5 Nausea & 4 & 1034 & Risk Ratio (M-H, Fixed, 99\% Cl) & $0.95[0.52,1.73]$ \\
\hline 3.6 Somnolence & 6 & 1206 & Risk Ratio (M-H, Fixed, 99\% Cl) & $1.93[1.22,3.06]$ \\
\hline
\end{tabular}

Analysis 1.1. Comparison 1 Gabapentin versus placebo, Outcome 1 Reduction in seizure frequency $\geq 50 \%$.

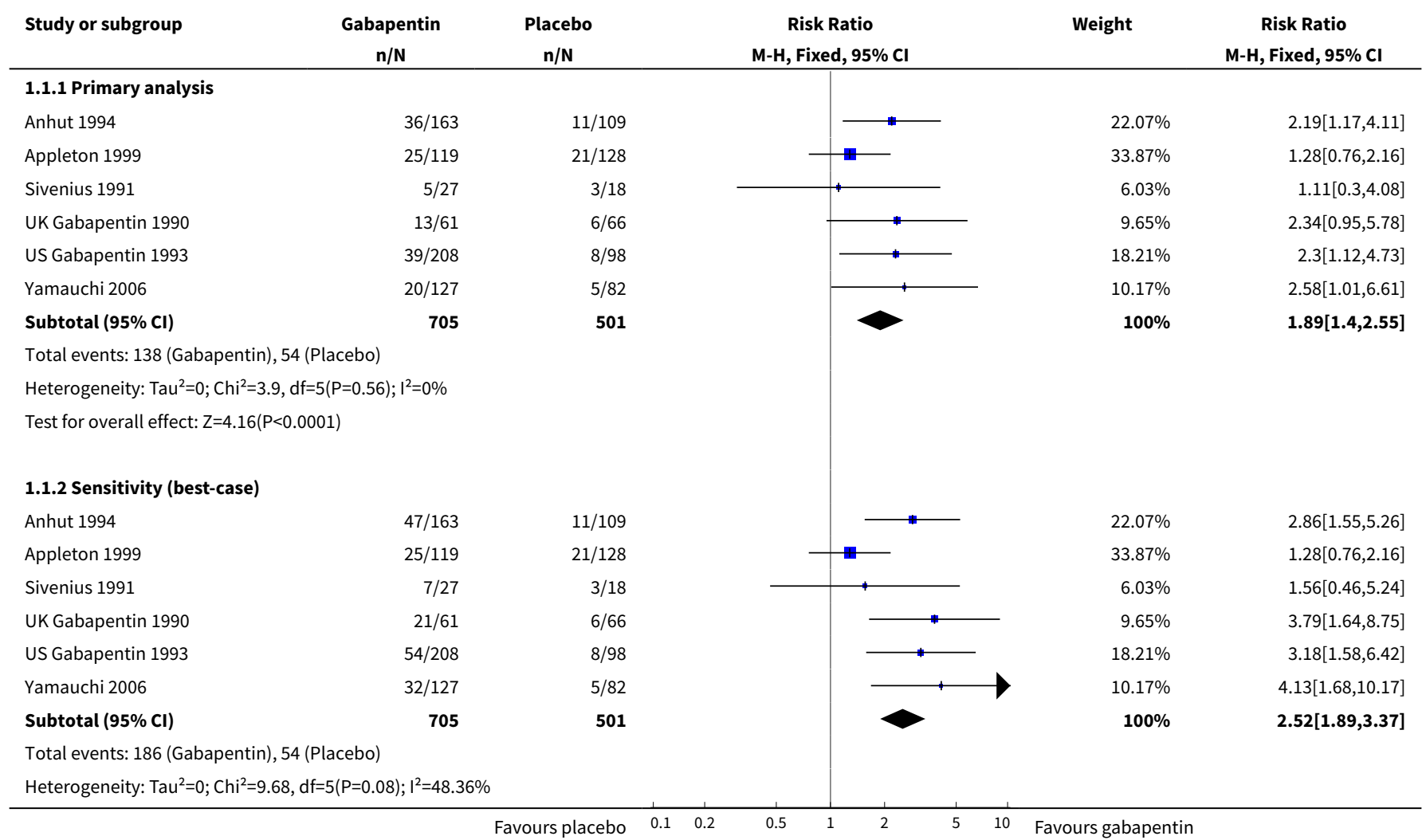




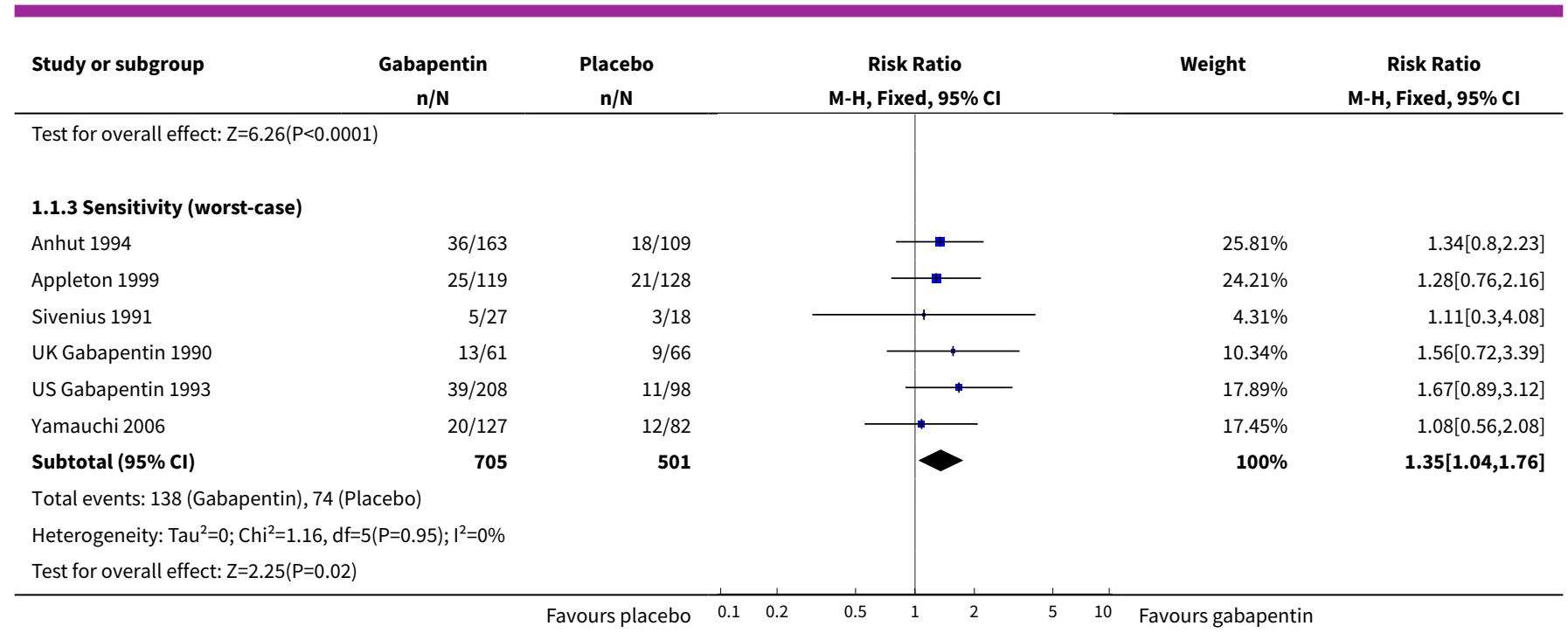

Analysis 1.2. Comparison 1 Gabapentin versus placebo, Outcome 2 Treatment withdrawal.

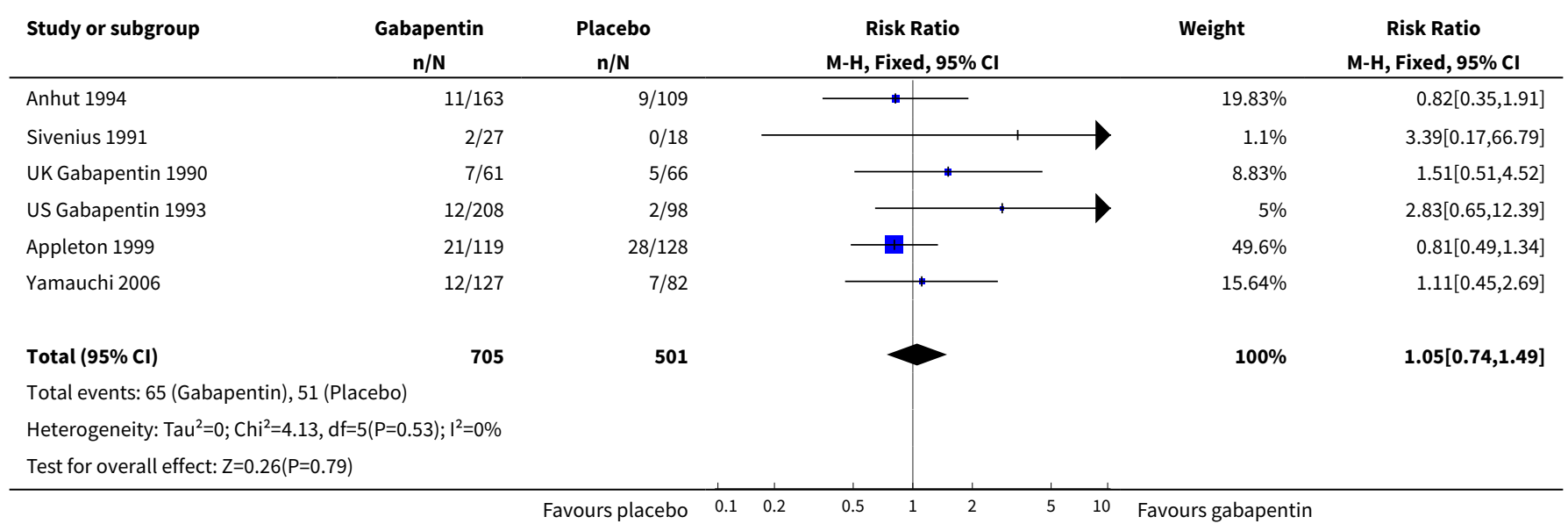

Analysis 1.3. Comparison 1 Gabapentin versus placebo, Outcome 3 Adverse effects.

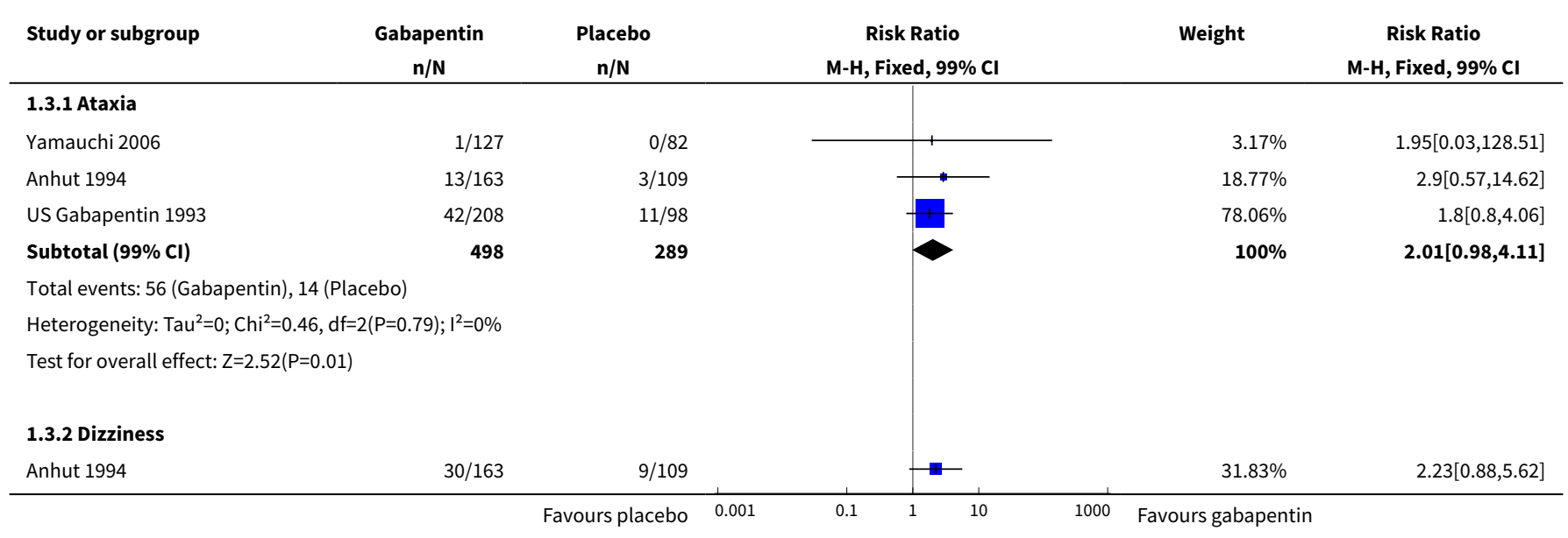




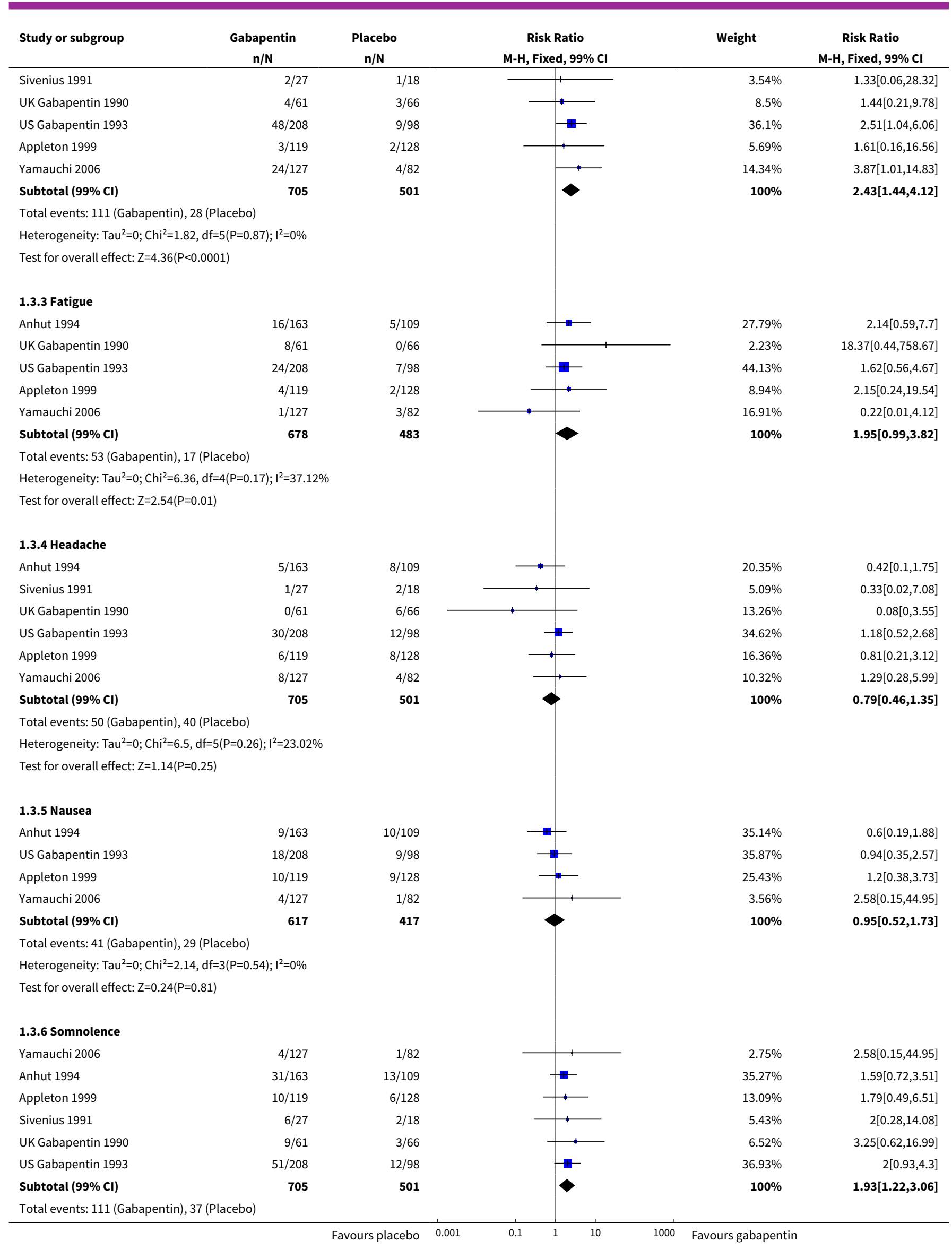




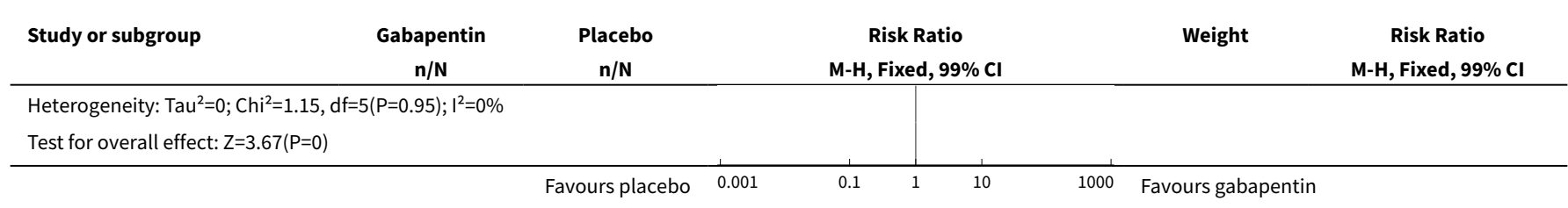

\section{ADDITIONAL TABLES}

Table 1. Estimated percentage responders and percentage difference compared to placebo per gabapentin dose, intention-to-treat

\begin{tabular}{lll}
\hline Dose & \% Responders (95\% Cl) & \% Difference (95\% Cl) compared to placebo \\
\hline $0 \mathrm{mg}$ (placebo) & $9.7(7.2$ to 12.9$)$ & $3.9(1.6$ to 6.2$)$ \\
\hline $600 \mathrm{mg}$ & $13.6(11.4$ to 16.1$)$ & $6.3(2.8$ to 9.8$)$ \\
\hline $900 \mathrm{mg}$ & $16.0(13.7$ to 18.6$)$ & $9.0(4.4$ to 13.7$)$ \\
\hline $1200 \mathrm{mg}$ & $18.7(15.8$ to 22.1$)$ & $15.5(8.5$ to 22.5$)$ \\
\hline $1800 \mathrm{mg}$ & $25.3(19.3$ to 32.3$)$ &
\end{tabular}

$\mathrm{Cl}$ : confidence interval.

Table 2. Estimated percentage responders and percentage difference compared to placebo per gabapentin dose, best-case

\begin{tabular}{lll}
\hline Dose & Responders \% (95\% Cl) & \% Difference (95\% Cl) compared to placebo \\
\hline $0 \mathrm{mg}$ (placebo) & $10.9(8.1$ to 14.5$)$ & $6.3(3.9$ to 8.8$)$ \\
\hline $600 \mathrm{mg}$ & $17.2(14.6$ to 20.2$)$ & 10.5 (6.8 to 14.2$)$ \\
\hline $900 \mathrm{mg}$ & $21.4(18.5$ to 24.6$)$ & $15.3(10.3$ to 20.0$)$ \\
\hline $1200 \mathrm{mg}$ & $26.2(22.4$ to 30.4$)$ & $26.7(19.3$ to 34.2) \\
\hline $1800 \mathrm{mg}$ & $37.6(30.0$ to 46.0$)$ & 2 \\
\hline
\end{tabular}

$\mathrm{Cl}$ : confidence interval.

Table 3. Estimated percentage responders and percentage difference compared to placebo per gabapentin dose, worst-case

\begin{tabular}{lll}
\hline Dose & Responders \% (95\% Cl) & \% Difference (95\% Cl) compared to placebo \\
\hline $0 \mathrm{mg}$ (placebo) & $13.8(10.4$ to 18.2$)$ & 2.5 (-0.3 to 5.3$)$ \\
\hline $600 \mathrm{mg}$ & $16.4(13.8$ to 19.2$)$ & \\
\hline
\end{tabular}


Table 3. Estimated percentage responders and percentage difference compared to placebo per gabapentin dose, worst-case (Continued)

\begin{tabular}{lll}
$900 \mathrm{mg}$ & $17.8(15.3$ to 20.5$)$ & $3.9(-0.3$ to 8.1$)$ \\
\hline $1200 \mathrm{mg}$ & $19.2(16.2$ to 22.7$)$ & $5.4(-0.2$ to 11.0$)$ \\
\hline $1800 \mathrm{mg}$ & $22.5(17.1$ to 29.0$)$ & $8.6(0.3$ to 17.0$)$
\end{tabular}

Cl: confidence interval. 


\begin{tabular}{|c|c|c|c|c|c|c|c|c|}
\hline Adverse effect & $\begin{array}{l}\text { Slow initiation (day } \\
\text { 2) }\end{array}$ & $\%$ & $\begin{array}{l}\text { Rapid initiation } \\
\text { (day 2) }\end{array}$ & $\%$ & $\begin{array}{l}\text { Slow initiation (day } \\
\text { 7) }\end{array}$ & $\%$ & $\begin{array}{l}\text { Rapid initiation } \\
\text { (day 7) }\end{array}$ & $\%$ \\
\hline Fatigue & $9 / 280$ & 3.2 & $12 / 294$ & 4.1 & $19 / 274$ & 6.9 & $22 / 294$ & 7.5 \\
\hline Dizziness & $18 / 280$ & 6.4 & $31 / 294$ & 10.5 & $45 / 276$ & 16.3 & $59 / 293$ & 19.1 \\
\hline Somnolence & $13 / 280$ & 4.6 & $16 / 294$ & 5.4 & $27 / 275$ & 9.8 & $31 / 293$ & 10.6 \\
\hline Ataxia & $2 / 280$ & 0.7 & $4 / 294$ & 1.4 & $9 / 275$ & 3.3 & $9 / 294$ & 3.1 \\
\hline
\end{tabular}




\section{APPENDICES}

\section{Appendix 1. Cochrane Register of Studies search strategy}

1. (gabapentin or Neurontin) AND INREGISTER AND >03/11/2016:CRSCREATED

2. gabapentin or Neurontin AND CENTRAL:TARGET

3. MESH DESCRIPTOR Epilepsy EXPLODE ALL AND CENTRAL:TARGET

4. MESH DESCRIPTOR Seizures EXPLODE ALL AND CENTRAL:TARGET

5. epilep* OR seizure* OR convuls* AND CENTRAL:TARGET

6. \#3 OR \#4 OR \#5 AND CENTRAL:TARGET

7. \#2 AND \#6 AND CENTRAL:TARGET

8. (monotherap* NOT (adjunct* OR "add-on" OR "add on" OR adjuvant* OR combination* OR polytherap*)):TI AND CENTRAL:TARGET

9. \#7 NOT \#8 AND CENTRAL:TARGET

10. >03/11/2016:CRSINCENTRAL AND CENTRAL:TARGET

11. \#9 AND \#10 AND CENTRAL:TARGET

12. \#1 OR \#11

\section{Appendix 2. MEDLINE (Ovid) search strategy}

This strategy was based on the Cochrane Highly Sensitive Search Strategy for identifying randomised trials (Lefebvre 2011).

1. (gabapentin or neurontin).tw.

2. exp Epilepsy/

3. exp Seizures/

4. (epilep\$ or seizure\$ or convuls\$).tw.

5.2 or 3 or 4

6. exp *Pre-Eclampsia/ or exp *Eclampsia/

7.5 not 6

8. (randomized controlled trial or controlled clinical trial or pragmatic clinical trial).pt. or (randomi?ed or placebo or randomly).ab.

9. clinical trials as topic.sh.

10. trial.ti.

11. 8 or 9 or 10

12. exp animals/ not humans.sh.

13. 11 not 12

14. 1 and 7 and 13

15. (monotherap\$ not (adjunct\$ or "add-on" or "add on" or adjuvant\$ or combination\$ or polytherap\$)).ti.

16. 14 not 15

17. remove duplicates from 16

18. limit 17 to ed=20161103-20180320 
19. 17 not (1\$ or $2 \$) . e d$.

20.19 and (2016\$ or $2017 \$$ or $2018 \$) . d t$.

21. 18 or 20

Appendix 3. ClinicalTrials.gov search strategy

Epilepsies, Partial | Gabapentin | First posted on or after 11/03/2016

\section{Appendix 4. ICTRP search strategy}

Condition: epilepsy

Intervention: gabapentin

Date of registration between 11/03/2016 and 20/03/2018

\section{WHAT'S NEW}

\begin{tabular}{lll}
\hline Date & Event & Description \\
\hline 20 March 2018 & $\begin{array}{l}\text { New citation required but conclusions } \\
\text { have not changed }\end{array}$ & Conclusions are unchanged. \\
\hline 20 March 2018 & New search has been performed & $\begin{array}{l}\text { Searches updated 20 March 2018; one new study has been in- } \\
\text { cluded. }\end{array}$ \\
& $\begin{array}{l}\text { The term 'partial' has been replaced by 'focal', in accordance } \\
\text { with the most recent classification of epilepsies of the Interna- } \\
\text { tional League Against Epilepsy (Scheffer 2017). }\end{array}$ \\
\hline
\end{tabular}

\section{H I S T O R Y}

Protocol first published: Issue 1, 1999

Review first published: Issue 1, 1999

\begin{tabular}{lll}
\hline Date & Event & Description \\
\hline 14 May 2013 & New search has been performed & Searches updated 14 May 2013. \\
\hline 14 May 2013 & $\begin{array}{l}\text { New citation required but conclusions } \\
\text { have not changed }\end{array}$ & Six new studies included. Conclusions remain unchanged. \\
\hline 10 September 2008 & Amended & Converted to new review format. \\
\hline 1 July 2007 & New search has been performed & $\begin{array}{l}\text { We re-ran our searches on 1 July 2007. One potential new study } \\
\text { has been identified - this has been added to the 'Studies await- } \\
\text { ing classification' section and will be assessed for inclusion at a } \\
\text { later date. }\end{array}$ \\
\hline
\end{tabular}

\section{CONTRIBUTIONS OF AUTHORS}

MP independently assessed trials for inclusion in the present update.

$\mathrm{SAB}$ and $\mathrm{J}$ Weston carried out the previous update of this review. 
JLH and JW completed the dose-regression analysis.

AGM and JLH developed the original protocol.

\section{DECLARATIONS OF INTEREST}

SB: none known.

JW: none known.

MP: none known.

JLH: none known.

AGM: a consortium of pharmaceutical companies (GSK, EISAI, UCB Pharma) funded the National Audit of Seizure Management in Hospitals (NASH) through grants paid to the University of Liverpool. Professor Tony Marson is part funded by National Institute for Health Research Collaboration for Leadership in Applied Health Research and Care North West Coast (NIHR CLAHRC NWC).

\section{SOURCES OF SUPPORT}

\section{Internal sources}

- No sources of support supplied

\section{External sources}

- National Institute for Health Research, UK.

\section{DIFFERENCES BETWEEN PROTOCOLANDREVIEW}

The term 'partial' has been replaced by 'focal', in accordance with the most recent classification of epilepsies of the International League Against Epilepsy (Scheffer 2017).

\section{INDEX TERMS}

\section{Medical Subject Headings (MeSH)}

Anticonvulsants [administration \& dosage] [adverse effects] [ ${ }^{\star}$ therapeutic use]; Cyclohexanecarboxylic Acids [ ${ }^{\star}$ therapeutic use]; Drug Resistant Epilepsy [*drug therapy]; Drug Therapy, Combination [methods]; Epilepsies, Partial [ ${ }^{\star}$ drug therapy]; Gabapentin [administration \& dosage] [adverse effects] [ ${ }^{\star}$ therapeutic use]; Intention to Treat Analysis; Randomized Controlled Trials as Topic; gamma-Aminobutyric Acid [*therapeutic use]

\section{MeSH check words}

Adult; Child; Humans 